\title{
Multi-walled carbon nanotubes (MWCNTs)-reinforced ceramic nanocomposites for aerospace applications: a review
}

\author{
Karthikeyan Ramachandran ${ }^{1, *}$ (D), Vignesh Boopalan ${ }^{2}$, Joseph C. Bear ${ }^{3}$, and Ram Subramani ${ }^{4,5}$ \\ ${ }^{1}$ Department of Aerospace and Aircraft Engineering, Kingston University, Roehampton Vale Campus, London SW15 3DW, UK \\ ${ }^{2}$ Centre for $\mathrm{CO} 2$ Research and Green Technologies, VIT, Vellore, India \\ ${ }^{3}$ Department of Chemical and Pharmaceutical Sciences, Kingston University, Penrhyn Rd, Kingston upon Thames KT1 2EE, UK \\ ${ }^{4}$ Department of Mechanical Engineering, Sathyabama Institute of Science and Technology, Chennai, India \\ ${ }^{5}$ School of Maritime Management, Indian Maritime University, Chennai, India
}

Received: 10 September 2021

Accepted: 25 November 2021

Published online:

13 December 2021

(C) The Author(s) 2021

\begin{abstract}
Advances in the nanotechnology have been actively applied to the field of aerospace engineering where there is a constant necessity of high durable material with low density and better thermo-mechanical properties. Over the past decade, carbon nanotubes-based composites are widely utilised owing to its fascinating properties resulting in series of multidisciplinary industrial applications. Carbon nanotubes (CNTs) are rolled up sheets of carbon in nanoscale which offers excellent thermal and mechanical properties at lower density which makes them suitable reinforcement for composites in aerospace applications. Owing to its high Young's modulus and chemically inert behaviour, CNTs are forefront of material research with applications varying from water purification to aerospace applications where applicational sector remains a mystery. Although there has been numerous research on the CNTs-based materials, there are only limited studies focusing on its utilisation for the field of aerospace engineering. As a result, in this review, we intend to cover the processing and synthesis techniques, thermal and mechanical properties as well as few industrial applications of CNTs-reinforced ceramic composites. Further, any potential development in additive manufacturing-based technique for fabricating $\mathrm{CNT} /$ ceramics and its applications in aerospace industries have been highlighted.
\end{abstract}

Handling Editor: Catalin Croitoru.

Address correspondence to E-mail: K1825123@kingston.ac.uk 


\section{Abbreviations}

CNTs

SWCNTs

MWCNTs

CVD

$\mathrm{Fe}$

Co

TCCVD

$\mathrm{C}_{2} \mathrm{H}_{2}$

$\mathrm{H}_{2}$

$\mathrm{CH} 4$

Sol-gel

$\mathrm{SrTiO}_{3}$

$\mathrm{Mg}$

CMCs

TEOS

$\mathrm{TiO}_{2}$

HPP

SPS

YSZ

CTAB

$\mathrm{SiO}_{2}$

$\mathrm{Al}_{2} \mathrm{O}_{3}$

$\mathrm{SiC}$

SDS

GA

$\mathrm{MnO}_{2}$

$\mathrm{Ni}$

$\mathrm{Ar}$

$\mathrm{MgO}$

$\mathrm{FeCl}_{3}$

$\mathrm{Sc}_{2} \mathrm{Si}_{2} \mathrm{O}_{7}$

$\mathrm{Ni}\left(\mathrm{NO}_{3}\right)_{2} \cdot 6 \mathrm{H}_{2} \mathrm{O}$

$\mathrm{Fe}\left(\mathrm{NO}_{3}\right)_{3} \cdot 9 \mathrm{H}_{2} \mathrm{O}$

$\mathrm{TiB}_{2}$

$\mathrm{Si}_{3} \mathrm{~N}_{4}+\mathrm{Lu}_{2} \mathrm{O}_{3}$

$\mathrm{ZrO}_{2}$

$\mathrm{AM}$

TPI

DSM Novamid ${ }^{\circledR}$

ID1030 CF10

C

FDM

$\mathrm{ZrO}_{2}$
Carbon nanotubes

Single-walled carbon nanotubes

Multi-walled carbon nanotubes

Chemical vapour deposition

Iron

Cobalt

Thermal catalyst chemical

vapour deposition

Acetylene

Hydrogen

Methane

Inorganic colloidal suspension

(sol) and gelation of the sol in a

continuous liquid phase (gel)

Strontium titanate

Magnesium

Ceramic matrix composites

Tetraethyl orthosilicate

Titanium oxide

Hot pressing process

Spark plasma sintering

Yttria-stabilised zirconia

Cetyl-trimethyl ammonium

bromide

Silicon oxide

Aluminium oxide (alumina)

Silicon carbide

Sodium dodecyl sulphate

Gallium

Manganese dioxide

Nickel

Argon

Magnesium oxide

Ferric chloride

Thortveitite

Nickel(II) nitrate hexahydrate

crystals

Iron(III) nitrate nonahydrate

Titanium diboride

Silicon nitride + lutetium oxide

Zirconium dioxide

Additive manufacturing

Thermosetting polyimide

New PA6/66 grade of carbon-

reinforced polyamide

Carbon

Fused deposition modelling

Zirconium oxide
NASA

JAXA

ISRO

TiC

EMI

HAP

UAV

VR

UV

$\mathrm{Cr}_{2} \mathrm{O}_{3}$

UHTCs

Hf

$\mathrm{Zr}$

\section{Introduction}

Interest towards the field of nanotechnology remains elevated in several disciplines of science due to its higher potential in areas involving engineering, agriculture and medicine. While the term "nanotechnology" has no approved definition, the products of nanotechnology are said to be measured at least less than $100 \mathrm{~nm}$ in any one dimension [1]. Being a specific component of nanotechnology, nanomaterials have attracted various researchers owing to its promising properties in mechanical, thermal and electronic disciplines. The multidisciplinary expansion of the nanomaterials depended on the support from industrial and academic sectors which included extremely funded research projects including National Nanotechnology Initiative (NNI) by US government in 2001. The NNI research supported the commercialisation, development and research on the field of nanotechnology with a budget of more than a $\$ 1$ billion [2]. Over past few decades, discovery and analysis on the properties of the nanomaterials have gained constant worldwide growth [3].

Carbon nanotubes (CNTs) are allotropes of carbon which exists in a quasi-one-dimensional structure which consists of graphite (carbon atoms) arranged in hexagonal structure creating a nanotube forming multiple layers [4]. CNTs are tube structured 
materials made from layers of graphite in nanoscale with varying outer diameter of $3-30 \mathrm{~nm}$. Some researchers consider the CNTs to be a derivative of both carbon fibres and fullerenes arranged in a muffled tube structure [5]. CNTs are generally classified by the number of carbon layers combined to form out the surface, i.e. single-walled carbon nanotubes (SWCNTs) where hexagonally structured single graphene layer varying diameter range of $0.4-5 \mathrm{~nm}$ and multi-walled carbon nanotubes (MWCNTs) which comprises of two or more sheets of the carbon with diameter range of 1-20 nm [6-8]. Though classification of CNTs depends on different layers of carbon, this allows them to have varying attributes. For instance, SWCNTs are suitable for electronic devices, sensors and field transmitters whereas mechanical-based applications prefer MWCNTs [9-11]. Being distinguished by the properties, synthesis techniques of the CNTs also vary as MWCNTs are simpler to produce compared to SWCNTs which require controlled growth and particular atmospheric conditions leading to difficulty in bulk synthesis [12, 13]. Further, synthesis technique also determines the purity of CNTs as most of the techniques are dependent on the catalysts and gases utilised during production. Several synthesis methods such as arc discharge, chemical vapour deposition (CVD), plasma rotation and hydrothermal processes are being developed to produce highquality CNTs as per the requirements of the research [14]. Chemical vapour deposition is one of the most common techniques which is utilised to synthesis CNTs. The CNTs formed through the technique depend on the various factors including temperature, atmospheric conditions, hydrocarbon source, catalysts and reactor type (i.e. horizontal or vertical). Typically, CVD technique involves agents like metal catalysts such as iron (Fe) or cobalt (Co) and hydrocarbon sources such as methane and ethylene [15].

Various researchers have utilised CVD-based techniques to synthesis CNTs by varying parameters such as catalysts, hydrocarbon sources which allowed them to control the growth and structure of CNTs [16-18]. For instance, Arunkumar et al. synthesised MWCNTs using thermal catalyst chemical vapour deposition technique (TCCVD) as illustrated in Fig. 1 by decomposition of $\mathrm{C}_{2} \mathrm{H}_{2}$ with $\mathrm{Fe} / \mathrm{MgO}$ as catalyst which was prepared by liquid impregnation. The technique resulted in MWCNTs with diameter of $\sim 20 \mathrm{~nm}$ and purity of $\sim 97 \%$ [14]. Alternatively,

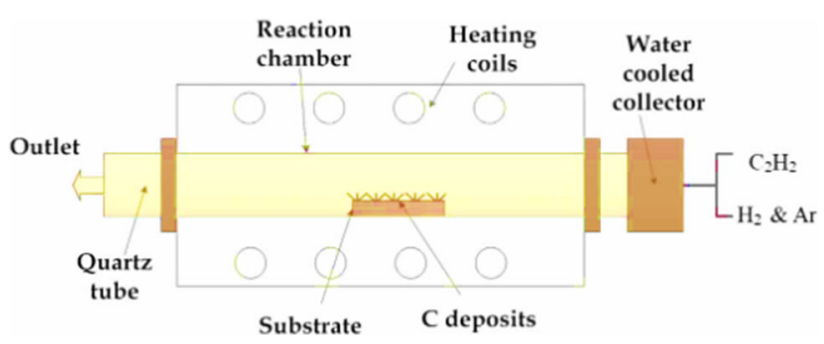

Figure 1 TCCVD technique set-up utilised for production of MWCNTs adapted from Arunkumar et al. with permission through rights link [14].

techniques like plasma rotation and arc discharge has also been utilised to synthesis CNTs along with CVDbased techniques. For instance, MWCNTs were first reported by Iijima et al. through arc discharge method while controlling the parameters to form fullerene [4]. Arc discharge method utilises high temperature $\left(>3000{ }^{\circ} \mathrm{C}\right)$ to evaporate carbon atoms into plasma forming SWCNTs or MWCNTs based on the atmospheric conditions. On the other hand, there has also been development with other techniques like plasma rotation and in situ emulsion polymerisation which have been capable of synthesising high-quality CNTs $[19,20]$. Flame synthesis is one of the recent techniques for producing CNTs in large volume compared to other techniques. Metallic-based catalyst particles, heat source and a source of carbon are the three main components for the synthesis of CNTs in flame synthesis. This process has potential to produce CNTs on any required surface, especially in highly controllable way [21, 22]. Through flame synthesis, single-walled carbon nanotubes (SWCNTs) have been observed formed in a premixed acetylene/ oxygen with $15 \mathrm{~mol} \%$ argon flame doped with 6100 ppm iron pentacarbonyl vapour and operated at a pressure of 50 Torr (6.7 $\mathrm{kPa})$ [23]. The parameters of this process are flexible and can be modified based on the required particle size and the growth of CNTs. These parameters include flame temperature, concentration of carbon specimen used, catalyst type, equivalence ratio and fuel type. The alignment is often desired and high purity of CNTs can be produced by using this process. Under the time frame of $1 \mathrm{~min}, \mathrm{CNTs}$ are formed with a typical length of 1-5 $\mathrm{m}$ and a mean diameter of 30-85 $\mathrm{nm}$ [24]. Carbon nano-onions were produced using enhanced acoustic modulation process in flame synthesis [25]. Flame synthesis is used and a substrate of iron-doped $\mathrm{Al}_{2} \mathrm{O}_{3}-\mathrm{ZrO}_{2}$ was used which is then catalysed 
decomposition of methane [26]. However, even with these techniques on place, CVD and its by techniques are considered to be the best way to produce CNTs owing to its cost effectiveness and high purity.

From its discovery, significant research has been constantly carried around CNTs on its synthesis, reinforcements and coating areas to explore the unique properties and applications. The distinctive properties and characteristics of the CNTs make them a potential reinforcement material in the field of engineering. CNTs have been utilised as reinforcing materials for metal and ceramics to improve its properties in various applications [27]. Nowadays, ceramics are preferred over metals and alloys owing to its thermal stability and lower density which make them a potential candidate in for structural, aerospace and industrial applications [28-30]. Although brittle nature of ceramics reduces its suitability in field of structural and aerospace applications. Various research has been conducted to enhance the fracture toughness of the ceramics by reinforcing them with various materials including metal and ceramic additives. Although with the potential of CNTs being a suitable reinforcement material, research work on incorporating CNTs has proved to be effective to ceramics composites as studies have demonstrated enhancement in fracture behaviour [31-33].

Although over the decade, there has been constant research on incorporating CNTs into by focusing on the processing techniques and properties of the composites. There is limited research on the proving the potentiality of CNTs-reinforced ceramic nanocomposites in the field of aerospace engineering by detailing fabrication technique and properties associated with the composites. Thus, this review intends to provide a comprehensive review on the processing and densification techniques associated with MWCNTs-reinforced ceramic composites with highlights towards the future manufacturing process, i.e. additive manufacturing. Further, potential applications of the CNTs-reinforced ceramics composites in aerospace and industrial sectors. The utilisation of the CNT/ceramic nanocomposites focused on the current concerns on the aerospace field such as structural, shielding, icing and barrier coatings.

\section{Processing techniques}

The remarkable stiffness, axial strength of CNTs with its stability in chemical and thermal environment makes them a unique and a crucial reinforcement to improve the mechanical properties of ceramics. Many studies reported marginal improvements mechanical properties after the CNT reinforcement [34, 35]. These results are dependent of CNTs synthesis techniques, composite processing method utilised by various researchers during their research. This section provides an overview on the different CNTs processing techniques associated with pre-processing of ceramic composites. The common CNTs processing techniques include sol-gel, powder metallurgy and in situ growth techniques. However, a colloidal route is also being followed by researchers around the world which is cheaper and time efficient compared to other processing techniques [33].

\section{Sol-gel route}

Sol-gel is one of the oldest processing methods available in the material science where highly pure composite powder could be produced owing to the controlled parameters in sol-gel operations [36, 37]. The technique could be utilised to distribute CNTs homogenously throughout the ceramic matrix with uniform crystalline size with help of ceramic precursors and control agents [38]. Figure 2 shows the schematics of the sol-gel process for forming CNTceramic powder through drying and calcination techniques. Though sol-gel is cheaper and sustainable method, the dispersion of CNT into ceramic is non-compatible owing to the hydrophobic nature of CNTs. Therefore, surfactants are required for dispersing CNTs into the aqueous solution [39]. Further
Figure 2 Schematic of CNTceramic processing through sol-gel technique.

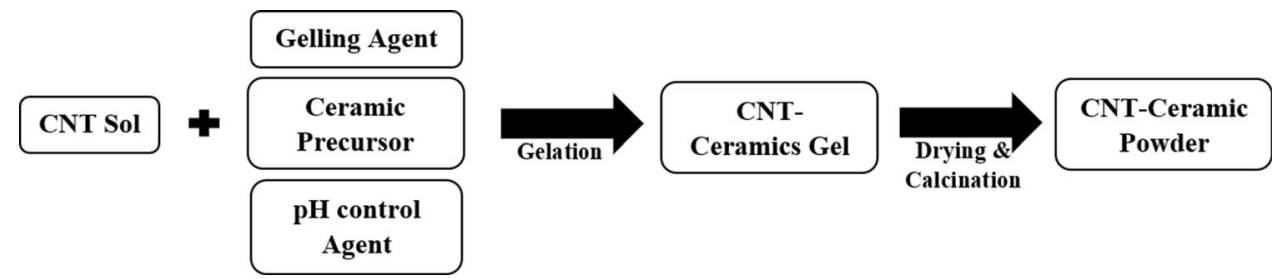


for uniform dispersion of the CNTs onto the matrices, external techniques are employed which enhances higher homogeneity on the composites. These external dispersion techniques involve physical methods such as ultrasonication, planetary ball milling and plasma and irradiation and chemical methods using organic and inorganic compounds which can interact with MWCNTs leading to dispersion [40]. Silva et al. created MWCNTs/zirconia and alumina-based ceramic composites by dispersing MWCNTs with help of dabcosil stearate and established that the MWCNTs were dispersed uniformly in high quantities on the sol [41]. Likewise, Lopez et al. prepared the sol-gel derived silica-reinforced MWCNTs coating using Tetraethyl orthosilicate (TEOS) as precursor and ethanol as gelling agent and physical techniques like ultrasonic probe and magnetic stirrer for enhancing distribution throughout the surfaces [42]. Similarly, Geo et al. prepared $\mathrm{CNTs} / \mathrm{TiO}_{2}$ composites through sol-gel process by dispersing MWCNTs using a sodium dodecylbenzene sulfonate surfactant and ultrasonication for uniform distribution of the MWCNTs [43]. However, few reports of Arunkumar et al. reported that the physical techniques were not able to be satisfactory in providing only through single physical techniques therefore he utilised two or more techniques to support higher homogeneous distribution. The report also specified that with increase in CNTs content, the rate of uniform distribution reduces owing to increase in Vander Waal force of attraction between CNTs particles [31].

\section{Powder metallurgy}

The simplest technique to fabricate any ceramics is said to be through powder metallurgy process. The techniques depend on different densification techniques including conventional techniques like pressureless sintering and non-conventional techniques like hot pressing process (HPP) and spark plasma sintering (SPS) by measuring the weight/ volume fractions of different materials required to form the final composite structure. Although conventional techniques of densifications are available, recent manufacturing trends have given raise to techniques like HPP and SPS which enhance the density of composites by compacting with high pressure. Powder metallurgy mostly depends on the mixing process where different techniques such as manual milling, ball milling, ultrasonication and other processes are involved [44, 45]. Arunkumar et al. fabricated MWCNTs/yttria-stabilised zirconia (YSZ) nanocomposites using SPS process as shown in the flow chart (Fig. 3). The authors mixed the MWCNTs with YSZ creating a slurry through ultrasonication, followed by magnetic stirring and further ball milling before drying using rotary evaporation [31]. Different researchers have worked with powder metallurgy for developing desired ceramic composites followed with various densification techniques [46]. Though powder technique is followed for synthesis of composite powders, the strength and properties of the powders depend on densification techniques which could lead to fatal effects to the composites leading to cracks on the samples or reduced density. Therefore, there is a constant demand to enhance the densification technique throughout the research area of materials science.

Along with powder processing, colloidal preparation route in which CNTs are dispersed into solvent using physical and chemical techniques is also followed to produce CNT-based nanofluid. The colloidal route of nanofluid preparation is a part of different fabrication techniques as it is applied to

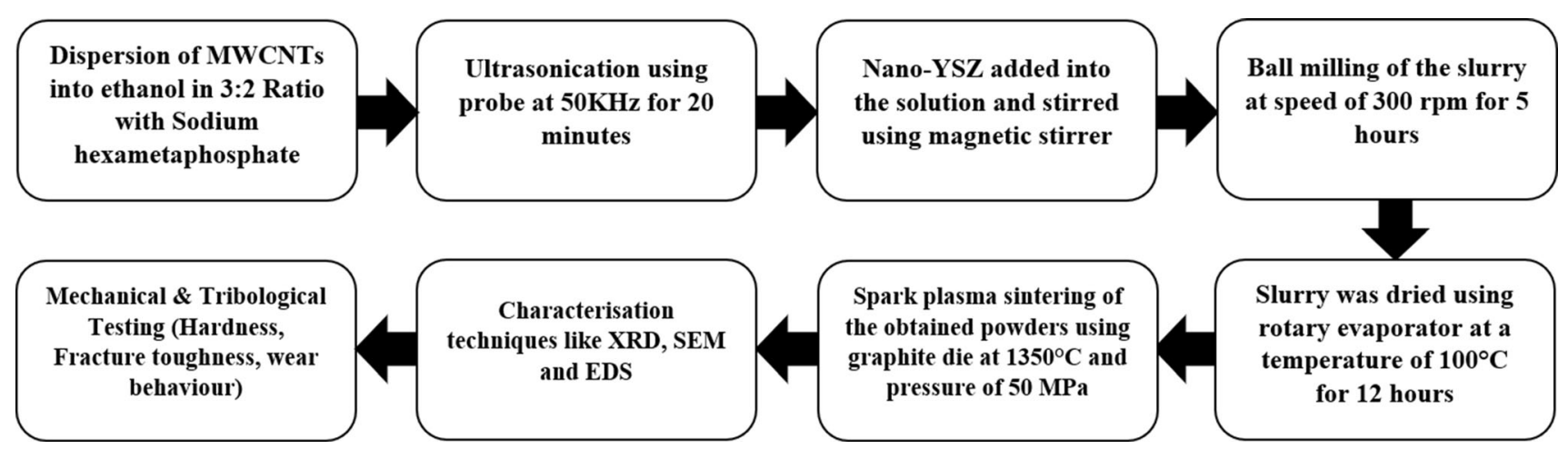

Figure 3 Powder processing technique schematics. 
Table 1 Colloidal route for dispersing ceramic matrix into MWCNT nanofluids

\begin{tabular}{|c|c|c|c|c|}
\hline Dispersion medium & Physical/chemical method & $\begin{array}{l}\text { Ceramic } \\
\text { matrix }\end{array}$ & Results/outcome & References \\
\hline $\begin{array}{l}\text { CTAB (cetyl- } \\
\text { trimethylammonium } \\
\text { bromide) }\end{array}$ & $\mathrm{N} / \mathrm{A}$ & $\mathrm{SiO}_{2}$ & $\begin{array}{l}\text { 97\% relatively dense ceramic composites of } \\
\mathrm{MWCNTs} / \mathrm{SiO}_{2}\end{array}$ & {$[49]$} \\
\hline Distilled water & $\begin{array}{l}\text { Polyethyleneimine and sonication for } \\
\text { two minutes }\end{array}$ & YTZP & $\begin{array}{l}\text { Higher dispersion with enhanced density, } \\
\text { toughness }\end{array}$ & {$[50]$} \\
\hline Deionised water & $\begin{array}{l}\text { Polyacrylic acid (PAA) and vigorous } \\
\text { stirring }\end{array}$ & Alumina & $\begin{array}{l}\text { Increased bending strength due to MWCNTs } \\
\text { pull-out }\end{array}$ & {$[51,52]$} \\
\hline Ethanol & $\begin{array}{l}\text { Sodium hexametaphosphate and } \\
\text { ultrasonication }\end{array}$ & $\mathrm{SiC} / \mathrm{YSZ}$ & $\begin{array}{l}\text { Improvement in fracture toughness with } \\
\text { reduction in other mechanical properties }\end{array}$ & {$[31,32]$} \\
\hline $\begin{array}{l}\text { SDS solution/distilled } \\
\text { water/gum Arabica }\end{array}$ & $\begin{array}{l}\text { Ultrasonic bath for } 6 \mathrm{~h} \text { followed by } \\
\text { ball milling for } 8 \mathrm{~h}\end{array}$ & Alumina & $\begin{array}{l}\text { GA and SDS mixture-based composite shown } \\
\text { improved electrical properties }\end{array}$ & {$[53]$} \\
\hline $\begin{array}{l}\text { Distilled water/ } \\
\text { acetone/ } \\
\text { ethanol }\end{array}$ & $\begin{array}{l}\text { Sonication and electrophoretic } \\
\text { deposition }\end{array}$ & $\mathrm{SiC}$ & $\begin{array}{l}\text { Higher dispersion and homogenous } \\
\text { distribution of MWCNTs }\end{array}$ & {$[54]$} \\
\hline Deionised water & $\begin{array}{l}\text { PAA with ammonium salt with } \\
\text { ultrasonication and mechanical } \\
\text { agitation }\end{array}$ & YTZP & $\begin{array}{l}\text { Fracture toughness of the samples increased } \\
\text { with reduction in hardness was observed }\end{array}$ & {$[55]$} \\
\hline Distilled water & Ultrasonication & $\begin{array}{l}\text { Alumina } \\
\text { and } \\
\mathrm{SiC}\end{array}$ & $\begin{array}{l}\text { Superior hardness with high stability between } \\
\text { SiC and MWCNTs were observed }\end{array}$ & {$[56]$} \\
\hline Ethanol & $\begin{array}{l}\text { Phosphate ester and } \\
\text { cresolsulfonphthalein were } \\
\text { surfactants with ultrasonication }\end{array}$ & $\mathrm{MnO}_{2}$ & $\begin{array}{l}\text { Electrical conductivity of the composites } \\
\text { increased with promising electrochemical } \\
\text { performance }\end{array}$ & {$[57]$} \\
\hline Distilled water & $\begin{array}{l}\text { Sonication for } 1 \mathrm{~h} \text { followed with } \\
\text { stirring }\end{array}$ & Alumina & Enhanced electrical conductivity & {$[58]$} \\
\hline
\end{tabular}

distribute the nanotubes homogenously. In this route, a nanofluid of CNTs is formed through dispersing CNTs into a solvent along with dispersing agent before addition of the ceramic to the solution and dried leading to enhanced CNT distribution. This is followed by processes such as drying and densification leading to the formation of a pellet. Goyny et al. utilised the colloidal route for fabricating MWCNTreinforced epoxy composites by dispersing MWCNTs into an acetone solution before sonication for $30 \mathrm{~min}$ and slow addition to heated epoxy resin [47]. Likewise, Arunkumar et al. utilised colloidal route for dispersing the MWCNTs into nano-SiC with help of chemical dispersing agent and ethanol as medium [32]. Table 1 shows the colloidal route followed by various researchers for dispersing MWCNTs into the ceramic matrix. Even though various colloidal techniques are available for ready usage electrophoretic deposition is widely used due to the higher dispersion rate onto the ceramic matrices [48]. As reported in Table 1, the dispersion medium and physical or chemical method is essential for enhancing the properties of MWCNT-reinforced ceramic matrix composites. Researchers utilise different surfactants which enhance the homogenous distribution and dispersion of CNTs into the medium. These processes (sol-gel, colloidal and powder metallurgy) require external action and further densification processes to be effective. The in situ growth technique only allows the CNTs to be grown directly on the surfaces of ceramic matrices which reduces the steps compared to CVD. The following section details the in situ growth process of MWCNT-reinforced ceramic matrix composites (Fig. 4).

\section{In situ growth}

The powder technique reported by many researchers for fabricating $\mathrm{CNT} / \mathrm{Al}_{2} \mathrm{O}_{3}$ and $\mathrm{CNT} / \mathrm{MgO}$-based composites through mixing or compacting ceramics with pre-grown CNTs powders followed by 


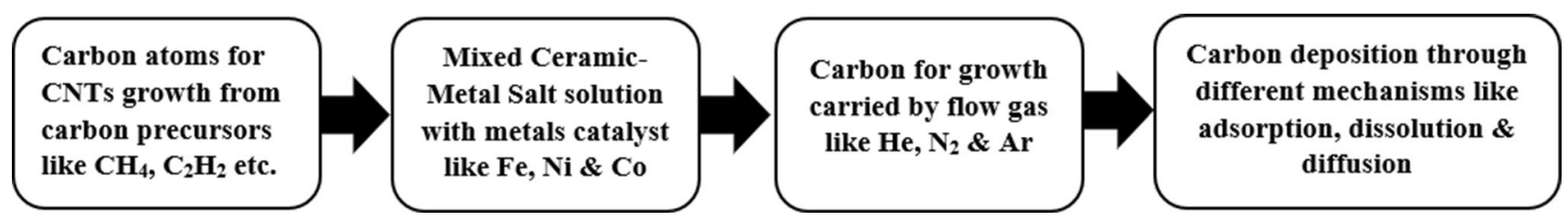

Figure 4 Schematics of in situ growth of CNTs onto the ceramics.

densification techniques. However, powder-based techniques require chemicals for enhancing diffusion such as surfactants, dispensing agents and physical methods like ball milling and ultrasonication to attain high order homogeneity. On the other hand, in situ growth of CNTs into the ceramics is advantageous as number of synthesis steps diminishes. This process utilises the nanopores on the ceramic body formed during sintering at high temperatures. These nanopores can be utilised as CNTs growing medium with help of a metal catalyst and a hydrocarbon source with a controlled growth temperature range of $700-1300{ }^{\circ} \mathrm{C}$ which must remain closer to the temperature of ceramic densification [59]. The growth technique enhances the homogenous dispersion of pure and high crystalline CNTs onto the ceramic substrate which tends to improve the mechanical properties and bonding between ceramics and CNTs. Chen et al. reinforced SiN by in situ growth of CNTs through chemical vapour infiltration which resulted in enhanced electrical conductivity as pores of $\mathrm{SiN}$ were connected through CNTs [60]. Sun et al. prepared CNT-reinforced $\mathrm{SiC}_{\mathrm{f}} / \mathrm{SiC}$ composites through CVD by utilising a polymer impregnation pyrolysis process. The growth method involved weaving $\mathrm{SiC}$ fibres into a 3D fibre format with nickel, aluminium and lanthanum nitrates used as catalysts for growing the CNTs. Figure 5 shows the microstructure of the growth of CNTs at different stages of the synthesis. Figure $5 \mathrm{a}$ shows the $\mathrm{SiC}$ fibres and Fig. $5 \mathrm{~b}$ the metallic catalysts covering $\mathrm{SiC}$ fibres in the preform. Figure $5 \mathrm{c}$ shows the feather growth of MWCNTs and Fig. $5 \mathrm{~d}$ the CNTs on single strand of SiC fibres. The in situ growth enhanced the mechanical properties of $\mathrm{SiC}_{\mathrm{f}} / \mathrm{SiC}$ which were due to the CNT pull-out mechanism [61].

Ding et al. grew CNTs for electromagnetic wave absorption by dissolving $\mathrm{FeCl}_{3}$-onto polysiloxanes in ethanol and calcined for $2 \mathrm{~h}$ in an argon atmosphere. The grown CNTs were characterised using Raman spectroscopy and it was determined that at $900{ }^{\circ} \mathrm{C}$, the size of CNTs was higher and with increase in
Figure 5 Growth of CNTs: a $\mathrm{SiC}$ fibre surface, $\mathbf{b} \mathrm{SiC}$ preform covered with metallic nanoparticles, $\mathbf{c}$ feature like CNT growth on $\mathrm{SiC}$ and d CNTs on SiC fibres adapted from the Sun et al. with permission [61].
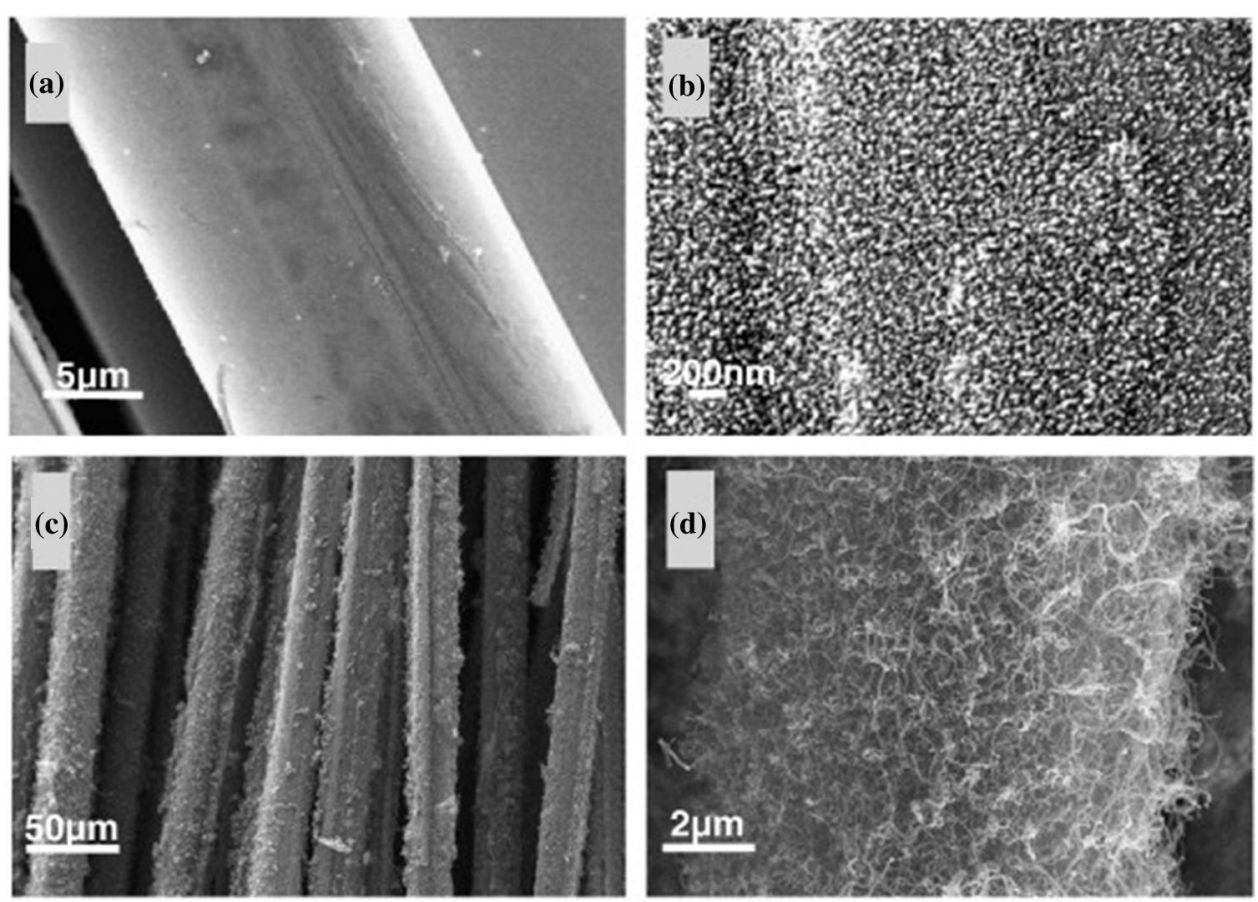
Table 2 Parameters and outcomes reported by researchers for in situ CNTs growth onto ceramics

\begin{tabular}{|c|c|c|c|c|c|c|}
\hline Atmosphere & $\begin{array}{l}\text { Time and } \\
\text { temperature }\end{array}$ & $\begin{array}{l}\text { Catalyst/ } \\
\text { medium }\end{array}$ & Precursor & $\begin{array}{l}\text { Ceramic } \\
\text { medium }\end{array}$ & Outcomes & References \\
\hline Nitrogen & $\begin{array}{c}700{ }^{\circ} \mathrm{C} \text { and } \\
120 \mathrm{~min}\end{array}$ & $\begin{array}{l}\text { Tetramethyl } \\
\text { ammonium } \\
\text { hydroxide \& } \\
\text { Sodium } \\
\text { hydroxide }\end{array}$ & Acetylene & Cobalt-zeolites & $\begin{array}{l}19.46 \% \text { CNTs were produced with } \\
\text { ID/Ig ratio } 0.88\end{array}$ & {$[18]$} \\
\hline Argon (Ar) & $\begin{array}{l}800-1500{ }^{\circ} \mathrm{C} \\
\text { and } 120 \mathrm{~min}\end{array}$ & $\begin{array}{l}\text { Iron(III) } \\
\text { Chloride } \\
\left(\mathrm{FeCl}_{3}\right)\end{array}$ & Ethanol & $\mathrm{SiC} / \mathrm{SiOC}$ & $\begin{array}{l}\text { Electromagnetic properties improved } \\
\text { drastically }\end{array}$ & {$[62]$} \\
\hline Argon $/ \mathrm{H}_{2}$ & $\begin{array}{l}780{ }^{\circ} \mathrm{C} \text { for } \\
30-120 \mathrm{~min}\end{array}$ & 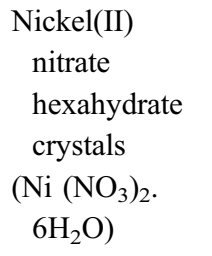 & $\begin{array}{l}\text { Camphor \& } \\
\text { acetone }\end{array}$ & $\begin{array}{l}\text { Porous } \\
\text { ceramics }\end{array}$ & $\begin{array}{l}\text { Prepared for air filtration and shown } \\
\text { good reusability for filter } \\
\text { applications }\end{array}$ & {$[63]$} \\
\hline Hydrogen & $\begin{array}{l}700{ }^{\circ} \mathrm{C} \text { for } \\
20 \mathrm{~min}\end{array}$ & $\begin{array}{l}\left(\mathrm{Ni}\left(\mathrm{NO}_{3}\right)_{2}\right. \\
6 \mathrm{H}_{2} \mathrm{O}\end{array}$ & Ethene & $\mathrm{Sc}_{2} \mathrm{Si}_{2} \mathrm{O}_{7}$ & $\begin{array}{l}\text { Electromagnetic waves absorption } \\
\text { material was prepared with high } \\
\text { bonded CNTs }\end{array}$ & {$[64]$} \\
\hline Hydrogen & $\begin{array}{l}800{ }^{\circ} \mathrm{C} \text { for } \\
150 \mathrm{~min}\end{array}$ & $\begin{array}{l}\mathrm{Fe} \\
\quad\left(\mathrm{NO}_{3}\right)_{3} \cdot 9 \mathrm{H}_{2} \mathrm{O}\end{array}$ & $\begin{array}{l}\text { Distilled } \\
\text { water }+\mathrm{NaOH}\end{array}$ & $\mathrm{TiB}_{2}$ & $\begin{array}{l}\text { CVD method was utilised for CNTs } \\
\text { growth onto } \mathrm{TiB}_{2} \text { matrix where } \\
\text { increasing Fe catalyst led to density } \\
\text { and diameter increase in CNTs }\end{array}$ & {$[17]$} \\
\hline Argon & $\begin{array}{l}550{ }^{\circ} \mathrm{C} \text { and } \\
60 \mathrm{~min}\end{array}$ & $\begin{array}{l}\text { Cobalt acetate } \\
\text { tetrahydrate }\end{array}$ & Acetone & $\mathrm{Si}_{3} \mathrm{~N}_{4}+\mathrm{Lu}_{2} \mathrm{O}_{3}$ & $\begin{array}{l}\text { CNTs grown } \mathrm{Si}_{3} \mathrm{~N}_{4} \text { composites } \\
\text { shown enhanced shielding } \\
\text { effectiveness for electromagnetic } \\
\text { shielding }\end{array}$ & {$[60]$} \\
\hline Nitrogen & $\begin{array}{l}2 \mathrm{~h} \text { and } \\
700{ }^{\circ} \mathrm{C}\end{array}$ & Ferrocene & Cyclohexanol & $\alpha$-Alumina & $\begin{array}{l}\text { Modified ceramic-alumina } \\
\text { composites have shown enhanced } \\
\text { copper absorption from water }\end{array}$ & {$[65]$} \\
\hline $\begin{array}{l}\text { Hydrogen } \\
\& \\
\text { nitrogen }\end{array}$ & $\begin{array}{l}750{ }^{\circ} \mathrm{C} \text { and } \\
60 \mathrm{~min}\end{array}$ & $\begin{array}{l}\text { Nickel nitrate, } \\
\text { aluminium } \\
\text { nitrate and } \\
\text { lanthanum } \\
\text { nitrate }\end{array}$ & Ethanol & $\mathrm{SiC}$ & $\begin{array}{l}\text { Improved mechanical properties due } \\
\text { to CNTs pull-out mechanism }\end{array}$ & {$[61]$} \\
\hline
\end{tabular}

temperature $\left(1500{ }^{\circ} \mathrm{C}\right)$, there was a steep decrease in size of CNTs up to $6.84 \mathrm{~nm}$ [62]. Table 2 displays the parameters and outcomes observed by various researchers. These studies reported that the in situ growth technique can be a viable method for CNT/ ceramic composite formation. Though the technique has been successful in growing CNTs over ceramic mediums as reported in Table 2. The technique was unable of growing CNTs in large surfaces.

\section{Densification techniques}

High-temperature sintering techniques are required for formating ceramic-based composites. The densification techniques enhance the bonding between the different powders present inside the composites leading to enhancement in mechanical and thermal properties. These treatments are critical for enhancing the interaction between the ceramics and CNTs by compressing and shaping the powders by supplying energy onto the matrices. This heat energy involved in the densification is utilised for breaking the bonds between the ceramics for superior bonding 
with the reinforcing material. Though the concept of the densification has been followed by different techniques, i.e. conventional and non-conventional to enhance the density of the composites. There are still developments being considered to achieve a high order densified sample. The sub-section below provides a brief on various densification techniques including the famed techniques like pressureless sintering, microwave-assisted sintering, hot press technique and SPS.

\section{Pressureless sintering}

Pressureless sintering is a thermal technique for densifying ceramic composites [38]. This sintering technique utilises the application of uniaxial hydraulic pressure to compress CNT/ceramic composites pellets followed with sintering of the pellets high-temperature furnace under varying temperature and atmospheric conditions depending on the material compressed as shown in schematics in Fig. 6. In case of $\mathrm{CNT} /$ ceramic nanocomposites, the atmospheric condition is preferred to be in vacuum environment with flow gas being $\mathrm{He}$, $\mathrm{Ar}$ and nitrogen rather than oxygen owing to the lower oxidation of CNTs in room environment [32]. The sintering temperature of the CNT/ceramic composites depends on the dominating material or matrix material in the composites, i.e. ceramics in case of ceramic/CNTs.

Zhang et al. improved the flexural strength of an alumina substrate by reinforcing with MWCNTs through the pressureless sintering process. MWCNTs were compacted into alumina at different compositions and uniaxially pressured and sintered at $1500{ }^{\circ} \mathrm{C}$ for $2 \mathrm{~h}$ using a tubular furnace with an argon atmosphere. The 1\% MWCNTs-reinforced alumina composites demonstrated $\sim 540 \mathrm{MPa}$ whereas pure alumina exhibited $\sim 400 \mathrm{MPa}$ for similar conditions [66]. Ahmad et al. fabricated $\mathrm{MgO}$ tailored alumina with 2\% MWCNTs using pressureless sintering with an external pressure of $40 \mathrm{MPa}$ and sintered at $1600{ }^{\circ} \mathrm{C}$ for $1 \mathrm{~h}$ under vacuum environment. The fabricated composites have shown a meagre mechanical response compared to hot pressed samples ostensibly due to poor microstructure formation. However, the pressureless sintered samples shown a slight increase in the mechanical properties compared to hot press technique. Figure 7a-f illustrates the fractured surface of pressureless sintered composites which shows numerous open pores representing the reduced densification on the surfaces $($ Fig. $7 a-c)$ whereas the pores are reduced with addition of $\mathrm{MgO}$ along with MWCNTs (Fig. $7 \mathrm{~d}-\mathrm{f}$ ) [67].

Likewise, Bakhsh et al. utilised pressureless sintering to fabricate CNT-alumina nanocomposites at $1700{ }^{\circ} \mathrm{C}$ for 15 min under an argon atmosphere and reported the fracture toughness of nanocomposites increased by $10 \%$ due to crack deflection, better dispersion and bridging mechanisms of the CNTs. However, densification of the composites decreased with increasing CNT content, leading to increased pore density and reduced hardness [68]. Further studies on the CNT/ceramic composites using pressureless sintering also exhibited improvement in the fracture toughness with reduction in density and hardness properties resulting in need of new sintering technique for increasing density along with reduction in porosity.

\section{Hot press technique}

The hot press technique is a non-conventional sintering method which involves high pressure for compaction the powder with subsequent high-temperature sintering [69]. The technique is also known as pressure-assisted sintering where pressure compresses the powder of $\mathrm{CNT} /$ ceramic into densified pellets or films. This technique increases the density of the composites due to the action of high pressure and temperature leading to enhanced bonding between the ceramics and reinforcement material which could increase the mechanical properties [70]. Mullite/MWCNTs-based composites were fabricated using the hot press method at $1600{ }^{\circ} \mathrm{C}$ which exhibited a $10 \%$ enhancement in bend strength and $78 \%$ increase in fracture toughness compared to monolithic mullite [71]. Numerous studies on the hot
Figure 6 Schematic of the pressureless sintering process.

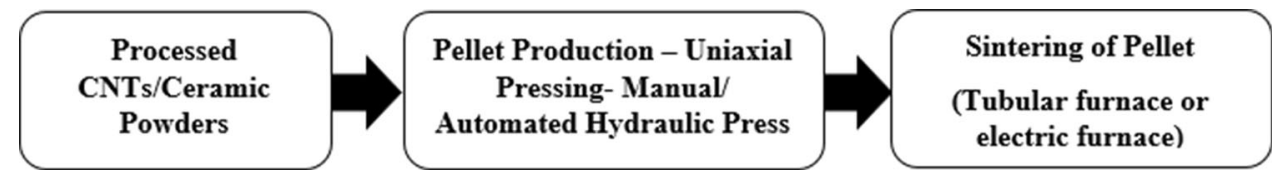


Figure 7 Microstructure of pressureless sintered: a $\mathrm{Al}_{2} \mathrm{O}_{3}$, b 300 ppm $\mathrm{MgO}-\mathrm{Al}_{2} \mathrm{O}_{3}$, c $600 \mathrm{ppm} \mathrm{MgO}-\mathrm{Al}_{2} \mathrm{O}_{3}$, d nanocomposite $\mathrm{Al}_{2} \mathrm{O}_{3}$ / MWCNTs, e 300 ppm MgO nanocomposite and $\mathbf{f} 600 \mathrm{ppm}$ $\mathrm{MgO}$ nanocomposites adapted from Ahmad et al. with permission [67].

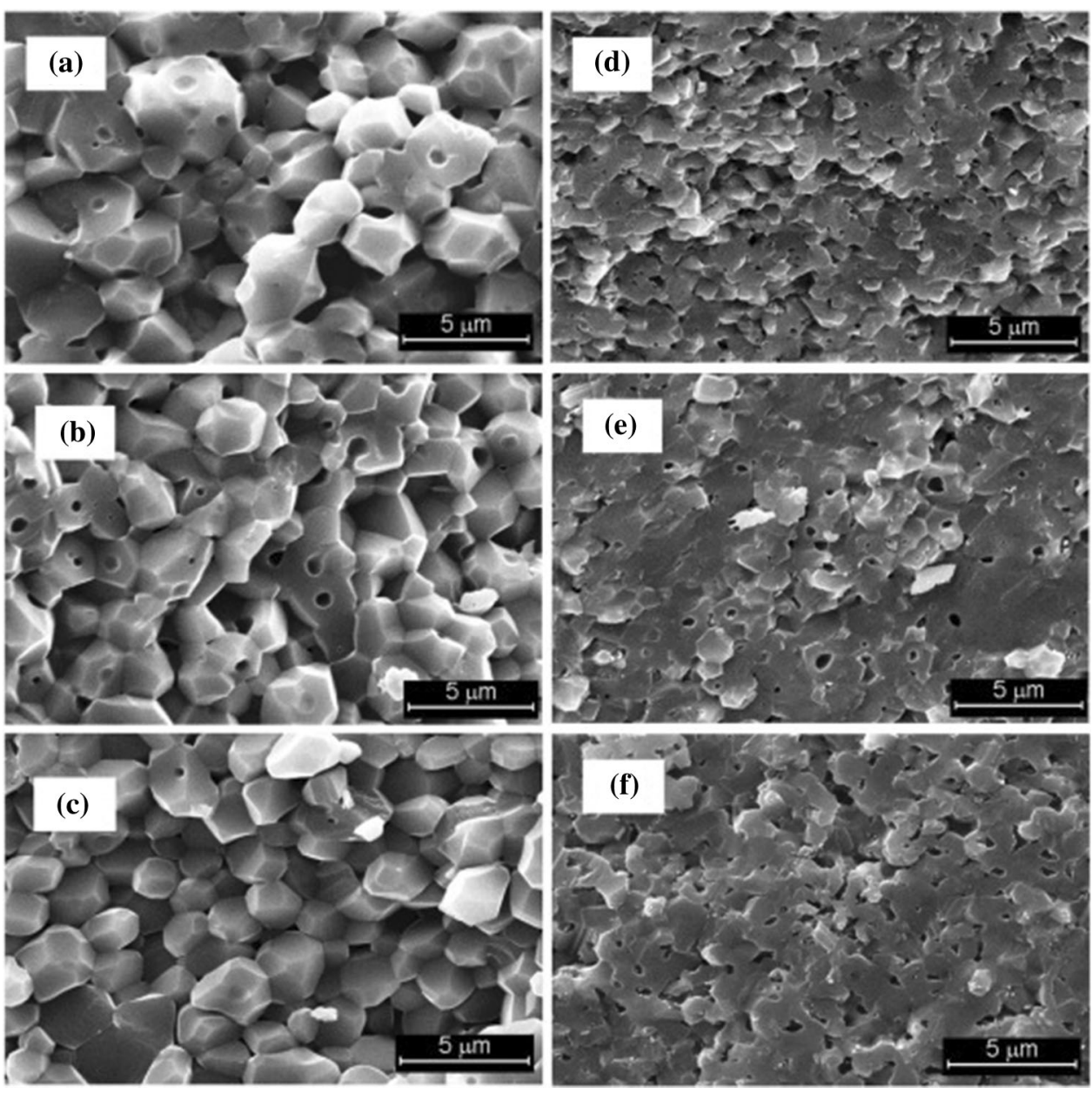

pressing of MWCNTs and ceramic nanocomposites have been carried out by researchers and few are reported in Table 3. The technique is said to enhance the density of the composites compared to the pressureless sintering and further provide with higher bonding between CNTs and ceramics due to continuous pressure being applied. The formed nanocomposites are said to be crack-free and dense owing to constant pressure and temperature. However, the technique could also damage the microstructure of the nanocomposites which may result in affecting the bonds between CNTs and ceramic present in the nanocomposites. Further, report studies till date have shown that the incorporation of CNTs into ceramics through hot pressing techniques only led to partial improvement in the properties. Therefore, there is a need to improve the densification behaviour of composites.

\section{Microwave-assisted sintering}

Microwave-assisted sintering is an emerging pressureless sintering method for fabricating CNT-CMCs with the help of electromagnetic fields (microwave). In this technique, powder metallurgy is utilised for processing CNT/ceramic pellets through physical and chemical process processes and pressed using hydraulic press at high pressure. Microwaves irradiate in the furnace allow ceramics to generate heat within the matrix due to joule's heating effect leading to internal interaction between the reinforcement and ceramics as illustrated in Fig. 8. Egorov et al. reported the fabrication of alumina ceramics reinforced with MWCNTs using microwave sintering at a temperature of $1500-1600{ }^{\circ} \mathrm{C}$ with a heating rate of $50-100{ }^{\circ} \mathrm{C} / \mathrm{min}$ with no hold time and determined that up to $2.5 \mathrm{wt} . \%$ of CNTs did not affect the thermal stability of the composites during rapid sintering of alumina [81]. Similarly, Ghobadi et al. densified 
Table 3 Various research on hot pressing technique of CNT/ceramic nanocomposites

\begin{tabular}{|c|c|c|c|c|}
\hline Ceramics & Temperature/pressure & $\begin{array}{l}\text { Processing } \\
\text { technique }\end{array}$ & Outcomes & References \\
\hline $\mathrm{SiN}$ & $\begin{array}{l}1700{ }^{\circ} \mathrm{C} \text { for } 60 \mathrm{~min} \\
\text { with } 2 \mathrm{MPa}\end{array}$ & $\begin{array}{l}\text { Ball milling \& } \\
\text { sonication }\end{array}$ & $\begin{array}{l}\text { MWCNTs survived after } 2 \mathrm{MPa} \text { with } 15-37 \% \\
\text { improvement in mechanical properties }\end{array}$ & [69] \\
\hline $\mathrm{Fe}-\mathrm{Al}_{2} \mathrm{O}_{3}$ & $\begin{array}{l}1355-1535^{\circ} \mathrm{C} \text { for } \\
15 \mathrm{~min}\end{array}$ & Selective reduction & $\begin{array}{l}\text { High dense composites with marginal increase in } \\
\text { Fracture toughness }\end{array}$ & {$[72]$} \\
\hline $\begin{array}{l}\text { BAS (Barium } \\
\text { Aluminosilicate) }\end{array}$ & $1600{ }^{\circ} \mathrm{C}$ for $60 \mathrm{~min}$ & $\begin{array}{l}\text { Ball milling \& } \\
\text { sonication }\end{array}$ & $\begin{array}{l}\text { Reinforcement with MWCNTs increased mechanical } \\
\text { properties than whiskers }\end{array}$ & {$[73]$} \\
\hline $\begin{array}{l}\text { Metal- } \\
\text { magnesium } \\
\text { aluminate spinal }\end{array}$ & $\begin{array}{l}1200-1500{ }^{\circ} \mathrm{C} \text { for } \\
20 \mathrm{~min} \text { with } \\
43 \mathrm{MPa}\end{array}$ & $\begin{array}{l}\text { Ball milling \& } \\
\text { sonication }\end{array}$ & $\begin{array}{l}\text { Hot press temperature was not enough to densify the } \\
\text { composites }\end{array}$ & {$[74]$} \\
\hline Alumina & $\begin{array}{l}1800{ }^{\circ} \mathrm{C} \text { for } 60 \mathrm{~min} \\
\text { with pressure of } \\
40 \mathrm{MPa}\end{array}$ & $\begin{array}{l}\text { Ball milling \& } \\
\text { sonication }\end{array}$ & $\begin{array}{l}\text { Wear resistance of composites increased up to } 4 \% \mathrm{CNT} \\
\text { but after } 4 \% \text { mechanical properties reduced }\end{array}$ & {$[75]$} \\
\hline Alumina & $\begin{array}{l}1500{ }^{\circ} \mathrm{C} \text { under } \\
\text { vacuum at } 40 \mathrm{MPa}\end{array}$ & $\begin{array}{l}\text { Purification of } \\
\text { MWCNTs and } \\
\text { ultrasonication }\end{array}$ & $\begin{array}{l}\text { Percolation increased by } 3.89 \mathrm{wt} \% \text {, enhanced electrical } \\
\text { properties }\end{array}$ & {$[76]$} \\
\hline $\mathrm{ZrO}_{2}$ & $1300{ }^{\circ} \mathrm{C}$ for $30 \mathrm{~min}$ & Colloidal route & $\begin{array}{l}\text { Decreased hardness and increased elastic resistivity of } 13 \\
\text { order of magnitude compared to monolithic zirconia }\end{array}$ & {$[77]$} \\
\hline $\mathrm{SiC}$ & $\begin{array}{l}2000{ }^{\circ} \mathrm{C} \text { at } 25 \mathrm{MPa} \\
\text { for } 60 \mathrm{~min}\end{array}$ & Ultrasonic shaker & $\begin{array}{l}\text { Bending strength of the composites and fracture } \\
\text { toughness increased over } 10 \% \text { than monolithic } \mathrm{SiC} \\
\text { through same purpose due to strengthening and } \\
\text { toughening role }\end{array}$ & {$[78]$} \\
\hline Borosilicate glass & $\begin{array}{l}750^{\circ} \mathrm{C} \text { in vacuum } \\
\text { for } 60 \mathrm{~min} \text { at } \\
5 \mathrm{MPa}\end{array}$ & $\begin{array}{l}\text { Ultrasonication for } \\
4 \mathrm{~h} \& \text { calcination } \\
\text { at } 350{ }^{\circ} \mathrm{C}\end{array}$ & $\begin{array}{l}\text { Monolithic ceramics were found to have higher } \\
\text { mechanical properties than fabricated composites }\end{array}$ & [79] \\
\hline $\mathrm{TiB}_{2}-\mathrm{SiC}$ & $1800{ }^{\circ} \mathrm{C}$ at $30 \mathrm{MPa}$ & $\begin{array}{l}\text { Ball milling with } \\
\text { different CNTs } \\
\text { compositions }\end{array}$ & $\begin{array}{l}\text { Addition of CNTs did not significantly affect the } \\
\text { composites in fracture toughness however, Vickers' } \\
\text { hardness reduced to } 21 \mathrm{GPa}\end{array}$ & {$[80]$} \\
\hline
\end{tabular}

alumina/MWCNTs composite through microwave sintering coated with boehmite nanoparticles. The samples were cold pressed at $180 \mathrm{MPa}$ and sintered at $1520{ }^{\circ} \mathrm{C}$ for $45 \mathrm{~min}$. The reinforced CNTs improved the fracture toughness by $\sim 37 \%$ with highly relative density [82]. However, like the pressureless sintering technique the density of the composite reduced with increase in CNTs content and further addition of CNTs led to decreased mechanical properties. Even though there have been studies on microwave-assisted sintering in different ceramic and metal matrix composites, the studies on CNT-reinforced ceramics are limited and further research is required.

\section{Spark plasma sintering (SPS)}

SPS is an emerging sintering technique for fabricating highly dense ceramics-based composites with help of electric pulse and continues pressure and temperature. The technique utilises three factors, i.e. pulse electric current, temperature and pressure to enhance the densification on the samples as represented in Fig. 9 where typically graphite-based die is employed with internal water-cooling circuits and DC pulse generator to generate heat. The SPS utilises uniaxial pressure and temperature simultaneously to increase the compression rate of the composites to enhance densification through providing the bond material with joule law of heating onto the surfaces [31]. The Joule's heating of the composites helps in improving the bond between the ceramics and CNTs. Various excellent reviews have been published on fabrication of CNT/ceramics through SPS processes along with its merits and demerits [38, 84]. Zhang et al. utilised SPS process for fabricating SWCNTsreinforced alumina composites with temperature of $1150{ }^{\circ} \mathrm{C}$ and pressure of $63 \mathrm{MPa}$ for dwell time of 
Figure 8 Microwave-assisted sintering furnace model adapted with permission [83].

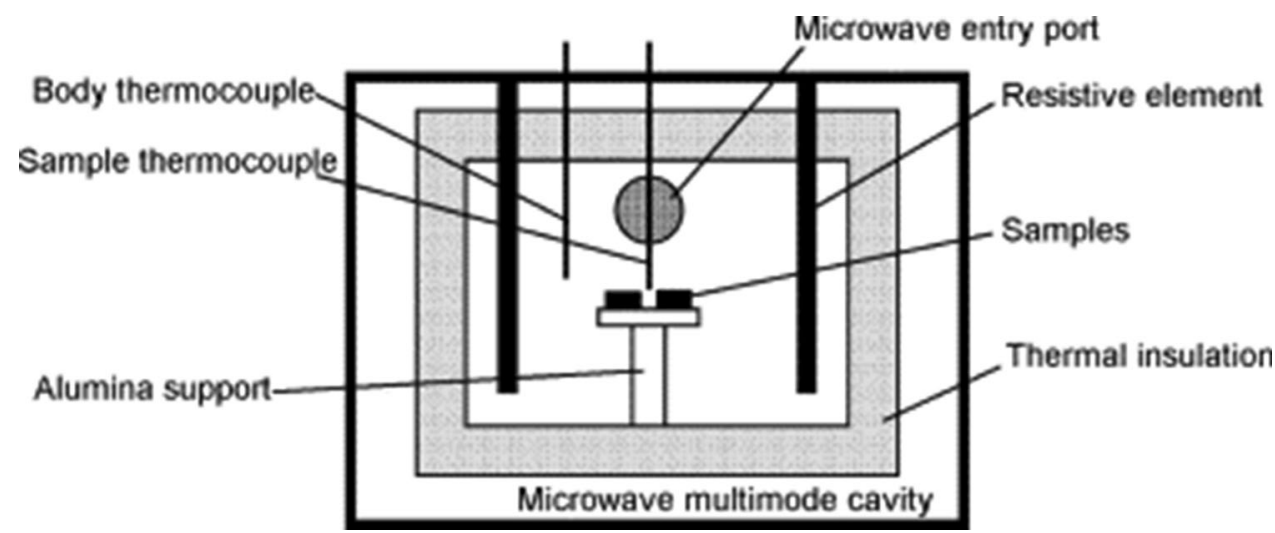

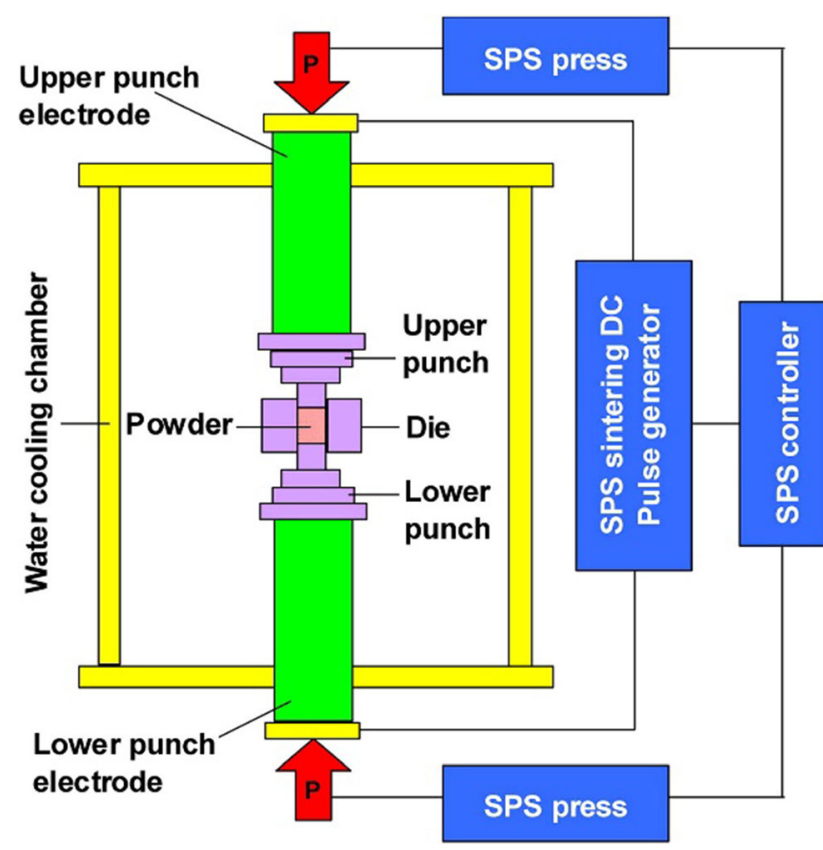

Figure 9 Schematics of spark plasma sintering adapted from Zhang et al. with permission [84].

3 min which enhanced the electrical conductivity and fracture toughness from 3.3 to $9.7 \mathrm{MPa}^{0.5}[85,86]$. These works inspired various researchers to concentrate on the SPS technique for fabricating CNT-reinforced ceramics as reported in Table 4. However, reports from Zhang et al. showed agglomeration of the CNTs and recent studies tried different powder processing techniques to avoid this problem [85, 86]. Arunkumar et al. have studied the fabrication of MWCNT-reinforced SiC and YSZ through SPS at various compositions by dispersing MWCNTs into the ceramic matrix through techniques like ultrasonication and ball millings process reported enhancement in fracture toughness of the nanocomposites [31, 32]. In contrast, Lopez et al. utilised SPS with carbon-based (graphene) reinforcement with YSZ and reported improved the fracture toughness and hardness along with significant improvement in electrical and thermal properties which contradicted hardness results reported by Arunkumar et al. [87]. Likewise, Momohjimoh et al. compared MWCNTs and SiC-doped alumina-based matrix and achieved lower-density composites with higher electrical conductivity ( 101.118 S/m) [88]. Arunkumar et al. higher weight percentage MWCNTs (15 wt.\%) study with nano-sized $\mathrm{SiC}$ reported an enhancement in the fracture toughness, but a drastic drop in hardness and impact strength [32]. In summary, an extensive study on SPS is still necessary to understand the optimisation of heat and properties of MWCNT-reinforced ceramics. Though SPS is an emerging technique, it's been widely utilised by researchers for fabricating composites with higher density. However, the technique tends to produce complex geometries and fabrication of large models through the technique is still impossible. So, there is a need for advance techniques which can produce complex models.

\section{Additive manufacturing of MWCNTs composites}

Even with significant advancements in the fabrication of MWCNT/ceramics composites, some investigations reported a partial increase or drastic drop in the density and other properties. Therefore, demand for advanced fabrication techniques which impart high densification and superior mechanical properties is highly sought-after. Additive manufacturing (AM) or $3 \mathrm{D}$ printing is one of the recent manufacturing processes which is one of the most promising future 
Table 4 Various reports on spark plasma sintering for ceramic/MWCNTs composites

\begin{tabular}{|c|c|c|c|c|}
\hline Ceramics & Temperature/pressure & $\begin{array}{l}\text { Powder processing } \\
\text { technique }\end{array}$ & Outcomes & References \\
\hline $\mathrm{Al}_{2} \mathrm{O}_{3}$ & $1500{ }^{\circ} \mathrm{C}$ with $20 \mathrm{MPa}$ & $\begin{array}{l}\text { Ball milling and } \\
\text { drying }\end{array}$ & $\begin{array}{l}\text { Negative effect on densification and better } \\
\text { mechanical properties }\end{array}$ & [89] \\
\hline $\mathrm{Al}_{2} \mathrm{O}_{3}$ & $1375^{\circ} \mathrm{C}$ in vacuum for $5 \mathrm{~min}$ & $\begin{array}{l}\text { Two-step process } \\
\text { with ultrasonication }\end{array}$ & $\begin{array}{l}\text { Fracture toughness of the composites increased } \\
\text { by } 2.5 \%\end{array}$ & {$[90]$} \\
\hline $\mathrm{Al}_{2} \mathrm{O}_{3}$ & $1000-1200{ }^{\circ} \mathrm{C}$ and $5-20 \mathrm{MPa}$ & $\begin{array}{l}\text { Sonication and slurry } \\
\text { technique }\end{array}$ & $\begin{array}{l}\text { Porous composite membrane was fabricated, and } \\
\text { best combination was revealed }\end{array}$ & {$[91]$} \\
\hline $\begin{array}{l}\mathrm{Al}_{2} \mathrm{O}_{3}- \\
\mathrm{SiC}\end{array}$ & $1500{ }^{\circ} \mathrm{C}$ for $10 \mathrm{~min}$ at $50 \mathrm{MPa}$ & $\begin{array}{l}\text { Slurry and } \\
\text { ultrasonication }\end{array}$ & $\begin{array}{l}\text { Increase in electrical conductivity making it } \\
\text { suitable for electric discharge machine }\end{array}$ & {$[92]$} \\
\hline $\begin{array}{c}\mathrm{Al}_{2} \mathrm{O}_{3}- \\
\mathrm{SiC}\end{array}$ & $\begin{array}{l}2000{ }^{\circ} \mathrm{C} \text { and } 50 \mathrm{MPa} \text { with dwell of } \\
10 \mathrm{~min} \text { and } \mathrm{Ag} \text { atmosphere }\end{array}$ & $\begin{array}{l}\text { Sonicator and slurry } \\
\text { drying }\end{array}$ & Increase in densification and fracture toughness & [93] \\
\hline $\mathrm{SiC}$ & $\begin{array}{l}1800{ }^{\circ} \mathrm{C} \text { and } 50 \mathrm{MPa} \text { with dwell time } \\
\text { of } 10 \mathrm{~min}\end{array}$ & $\begin{array}{l}\text { Ultrasonication and } \\
\text { rotary evaporator }\end{array}$ & $\begin{array}{l}\text { Improvement in fracture toughness up to } 5 \mathrm{wt} . \% \\
\text { CNTs addition }\end{array}$ & {$[32]$} \\
\hline $\mathrm{SiC}$ & $2000{ }^{\circ} \mathrm{C}$ and $73 \mathrm{MPa}$ & $\begin{array}{l}\text { Aqueous slurry and } \\
\text { drying }\end{array}$ & $\begin{array}{l}\text { Density and hardness increased with CNTs pull- } \\
\text { out mechanisms }\end{array}$ & {$[94]$} \\
\hline $\mathrm{SiC}$ & $1800^{\circ} \mathrm{C}$ & Diffusion process & $\begin{array}{l}\text { Outstanding thermal and electrical properties } \\
\text { were increased with CNT addition }\end{array}$ & {$[95]$} \\
\hline YSZ & $1200-1500{ }^{\circ} \mathrm{C}$ at $50 \mathrm{MPa}$ & Ball milling & $\begin{array}{l}\text { High CNTs dispersion could increase fracture } \\
\text { toughness }\end{array}$ & {$[96]$} \\
\hline YSZ & $\begin{array}{l}1350{ }^{\circ} \mathrm{C} \text { and } 50 \mathrm{MPa} \text { with dwell of } \\
10 \mathrm{~min}\end{array}$ & $\begin{array}{l}\text { Ultrasonication and } \\
\text { rotary evaporator }\end{array}$ & $\begin{array}{l}\text { Fracture toughness increased by } 21 \% \text { than YSZ } \\
\text { ceramic }\end{array}$ & [31] \\
\hline YSZ & $1300^{\circ} \mathrm{C}$ and $30 \mathrm{MPa}$ & $\begin{array}{l}\text { Ultrasonication and } \\
\text { ball milling }\end{array}$ & $\begin{array}{l}\text { Addition of CNT increase densification of YSZ } \\
\text { ceramic }\end{array}$ & [97] \\
\hline
\end{tabular}

avenues for research involving the commercial markets of the aerospace for preparing composites with high structural stabilities [98]. AM is a viable process for manufacturing complex customised prototypes with various developments in the machines and printable materials for small-scale production. Various research has been carried out on the AM of composites and its products [99, 100]. Likewise, research on 3D printing of CNT-based components is also being carried out around the world. Yu et al. created a novel 3D printing procedure for fabricating CNT-based micro-supercapacitors which uses solidcontaining CNT-ink. The printed micro-capacitors have shown excellent stability and significant areal capacitance [101]. Ye et al. printed CNT-reinforced thermoplastic polyimide composites by producing filament as illustrated in Fig. 10 for usage in aerospace structures by investigating the tensile and bending properties. The study reported that the CNT-reinforced composites showed superior performance and with further optimisation the complex aerospace components can be fabricated [102].
Li et al. printed carbon-reinforced polylactic acid composite and reported that the printed material showed increased interfacing strength along with $13.8 \%$ and $164 \%$ increased tensile and flexural strength than original carbon-fibre-reinforced samples [100]. 3D printing of $\mathrm{C} / \mathrm{SiC}$ composites material is one of the greatly researched areas with various researchers focusing on SiC-based $3 \mathrm{D}$ printable materials. Zhu and co-workers developed carbon-fibrereinforced $\mathrm{SiC}$ composites by combining $3 \mathrm{D}$ printing and infiltration processes. The green bodies (unsintered) were fabricated through $3 \mathrm{D}$ printing using phenolic resin-coated carbon fibre composites and vacuum infiltration was used to fabricate $C / C$ preforms. Liquid silicon was used for infiltrating $C / C_{f}$ preforms to attain the final $\mathrm{C} / \mathrm{SiC}$ composites [103]. The number of recent studies on $3 \mathrm{D}$ printing ceramics has increased exponentially over the last few years, mirroring trends seen metals and polymers [104]. 3D printing technologies for ceramics have been classified based on the feedstock utilised for printing, such as: slurry, powder or bulk techniques [105]. SiC reticulated porous ceramics were prepared by $3 \mathrm{D}$ 


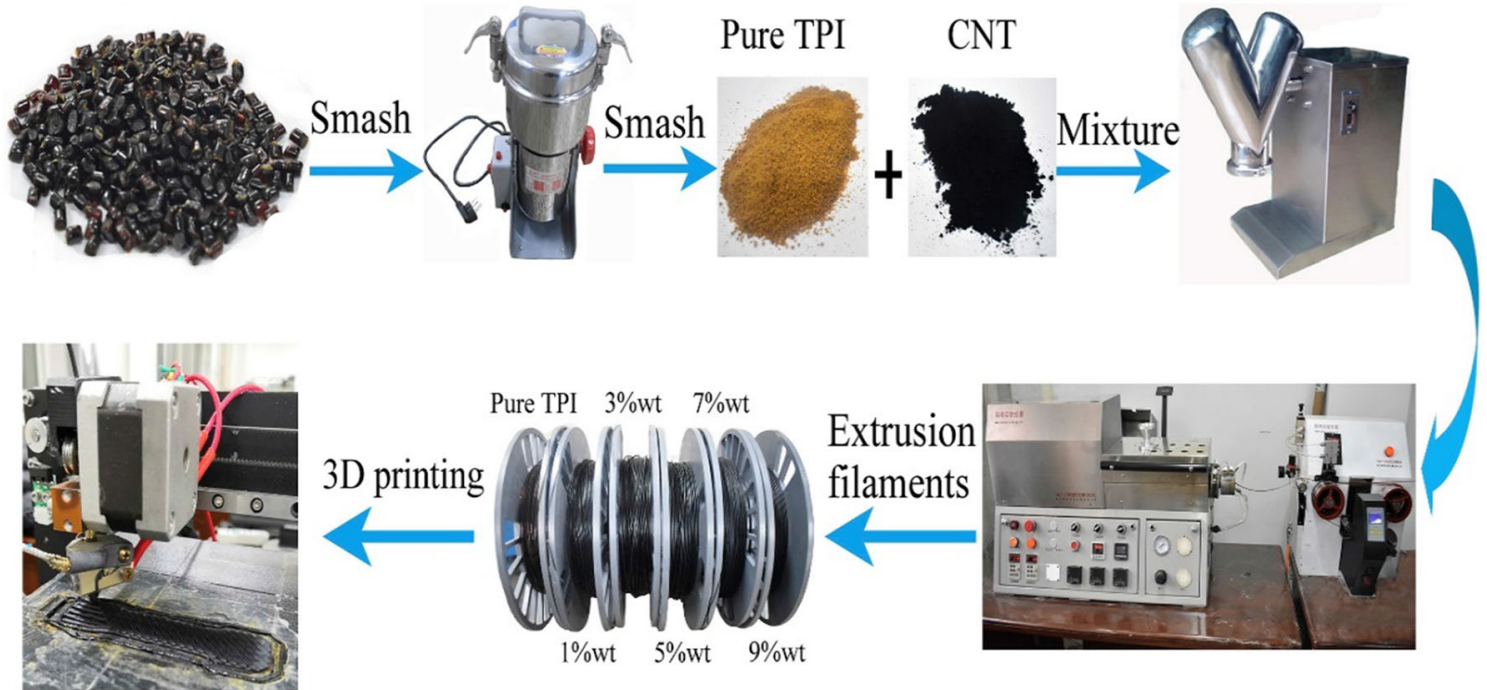

Figure $103 \mathrm{D}$ printing filament preparation schematics of CNT/TPI composites adapted from Ye et al. with permission [102].

printing with help of a polyvinyl alcohol mould, before the slurry was gel-casted into the surfaces [106]. Allahverdi and co-workers successfully printed ceramic-based transducers in different shapes through fused deposition modelling (FDM) technique, with help of polymers/piezoelectric ceramics (lead-zirconate-titanate and lead-magnesium-niobate) composites as feedstocks and demonstrated enhanced electrical properties [107]. Also, Blazdell et al. used ink-based feedstock for 3D printing of $\mathrm{ZrO}_{2}$ and $\mathrm{TiO}_{2}$ ceramics using small volume ink fractions led to poor surface quality [108]. To the best of knowledge and despite recent developments in the field, there have been no studies related to additive manufacturing of MWCNT/ceramic-based composite products. Further studies are necessary in AM for incorporating CNT-based ceramic composites for engineering or biomedical fields. Prior to developing advanced manufacturing process, there is a need to optimise current fabrication techniques to improve the densification behaviour and properties of the MWCNTs/ceramic nanocomposites. Table 5 details

Table 5 Advantages and disadvantages of various fabrication techniques

\begin{tabular}{|c|c|c|c|}
\hline $\begin{array}{l}\text { Fabrication } \\
\text { techniques }\end{array}$ & $\begin{array}{l}\text { Type of processing } \\
\text { techniques }\end{array}$ & Advantages & Disadvantages \\
\hline $\begin{array}{l}\text { Pressureless } \\
\text { sintering }\end{array}$ & Powder metallurgy & $\begin{array}{l}\text { Easy to utilise } \\
\text { Customisable to user }\end{array}$ & $\begin{array}{l}\text { Lack of pressure during sintering leads to cracks } \\
\text { and reduction in density }\end{array}$ \\
\hline $\begin{array}{l}\text { Microwave- } \\
\text { assisted sintering }\end{array}$ & Powder metallurgy & $\begin{array}{l}\text { Complete bonding between composite } \\
\text { elements is possible } \\
\text { Increased sintering effect }\end{array}$ & $\begin{array}{l}\text { Lack of pressure during sintering leads to cracks } \\
\text { and reduction in density }\end{array}$ \\
\hline $\begin{array}{l}\text { Hot pressing } \\
\text { method }\end{array}$ & $\begin{array}{l}\text { Powder metallurgy, } \\
\text { colloidal route }\end{array}$ & $\begin{array}{l}\text { High densified samples can be } \\
\text { achieved } \\
\text { Even surface throughout the } \\
\text { composites }\end{array}$ & $\begin{array}{l}\text { Chance in microstructure } \\
\text { Propagation of cracks }\end{array}$ \\
\hline $\begin{array}{l}\text { Spark plasma } \\
\text { sintering }\end{array}$ & $\begin{array}{l}\text { Powder processing } \\
\text { techniques }\end{array}$ & $\begin{array}{l}\text { Highly dense sample with less cracks } \\
\text { can be achieved } \\
\text { Durability of samples are high }\end{array}$ & $\begin{array}{l}\text { Small-scale samples } \\
\text { Traces of carbon in analysis due to presence of } \\
\text { graphite die }\end{array}$ \\
\hline $\begin{array}{l}\text { Additive } \\
\text { manufacturing }\end{array}$ & $\begin{array}{l}\text { Filament-based } \\
\text { technique } \\
\text { Powder-based } \\
\text { technique }\end{array}$ & $\begin{array}{l}\text { Any shape can be achieved as per user } \\
\text { needs } \\
\text { Optimised to enhance density and other } \\
\text { properties }\end{array}$ & $\begin{array}{l}\text { Still under development } \\
\text { Time taken for final products are higher } \\
\text { Expensive }\end{array}$ \\
\hline
\end{tabular}


the summary of advantages and disadvantages of different fabrication techniques reported in this review. By optimising the disadvantages of current fabrication techniques could lead to enhancement of the various properties associated with MWCNTs-reinforced ceramic composites.

\section{Properties of MWCNTs/ceramic composites}

Properties of MWCNT-reinforced ceramic composites have been a fascinating area of research with numerous groups focusing on enhancing the properties of the ceramics for various applications. Though there have been many reviews on the properties of the MWCNTs-reinforced ceramics composites including details on the failure mechanisms for diverse applications. Nevertheless, there is still a need to understand failure mechanisms and other physical behaviours in detail [38, 109]. The subsequent sub-section provides a brief overview on the properties and studies conducted on MWCNT-reinforced ceramic composites.

\section{Thermal properties}

Thermal behaviour of the materials plays an essential role in determining its usage in high-temperature applications such as aerospace and nuclear environments [38]. Studies have shown that the reinforcing CNTs can enhance the thermal properties of the material. This phenomenon is especially utilised for polymer and ceramic-based materials which are used to form composites designed to enhance mechanical and thermal properties. Use of ceramic-based composites has enhanced aerospace applications due to their superior thermo-mechanical properties compared to Ni-based superalloys and aluminium alloys which are currently the materials of choice in aerospace engineering for structural and turbine components. Basic thermal properties of any material involve conductivity, diffusivity, heat capacity and thermal expansion which highly depend on parameters like bulk density, sintering temperature and pressure on surface of the composites [110]. Kumari et al. prepared CNTs-alumina composites at varying composition and sintering temperatures and reported that the diffusivity of the material increased by $60 \%$ compared to monolithic alumina with $7.39 \mathrm{wt} \%$ of the composites for samples sintered at $1550{ }^{\circ} \mathrm{C}$ [111]. However, Ramachandran et al. reported a reduction of the diffusivity value with increase in CNT content with $1 \mathrm{wt} . \%$ showing the highest diffusivity value compared to the monolithic alumina fabricated via same technique [33]. Both research teams prepared the composites through SPS process with sintering temperature and dwell time playing a huge role in determining the diffusivity of the composites. However, the preparation aspect of the CNT/alumina differed from one another. On the other hand, Shah et al. fabricated a hybrid composite of graphene/ CNT/alumina through SPS (as shown in Fig. 11) and reported enhancement in the conductivity for $1 \mathrm{wt} . \%$ CNTs and 0.4 wt.\% graphene [112]. However, with $\mathrm{SiC}$ and CNTs as reinforcements in hybrid composites, thermal conductivity dropped at higher $\mathrm{SiC}$ content resulting in inferior thermal properties than CNT-reinforced composites [92].

Although there have been many literatures focusing on the thermal properties of the composites reinforced with CNTs as reported in Table 6, most of them concentrated on the effect of the wt.\% of CNTs and sintering temperature on the thermal properties, none reported on the mechanism which caused this enhancement [113]. According to Ramachandran et al., the twirled structure of the MWCNTs incorporated into the alumina matrix may block the travelling phonons. This leads to the reduction in thermal conductivity along with agglomeration of MWCNTs onto the matrix could reduce the phonon scattering due to Van der Waals forces of attraction between the MWCNTs which was also observed by Hazel et al. $[33,114]$. In contrast, Kumari et al. stated that the uniform dispersion of the MWCNTs onto the ceramic matrix could be reason for the increase in thermal conductivity [111]. Although researcher like Kumari et al. reported that homogeneous distribution of MWCNTs on the ceramic composites could have been the mechanism behind enhancing the thermal behaviour but that could be the basic mechanism behaviour the improvements. It is noteworthy that the mechanism proposed by Ramachandran et al. and Hazel et al. concentrates on the phonon scattering which is still an area of ongoing research.

\section{Mechanical properties}

Mechanical properties including hardness, fracture toughness and flexural strength are desirable 


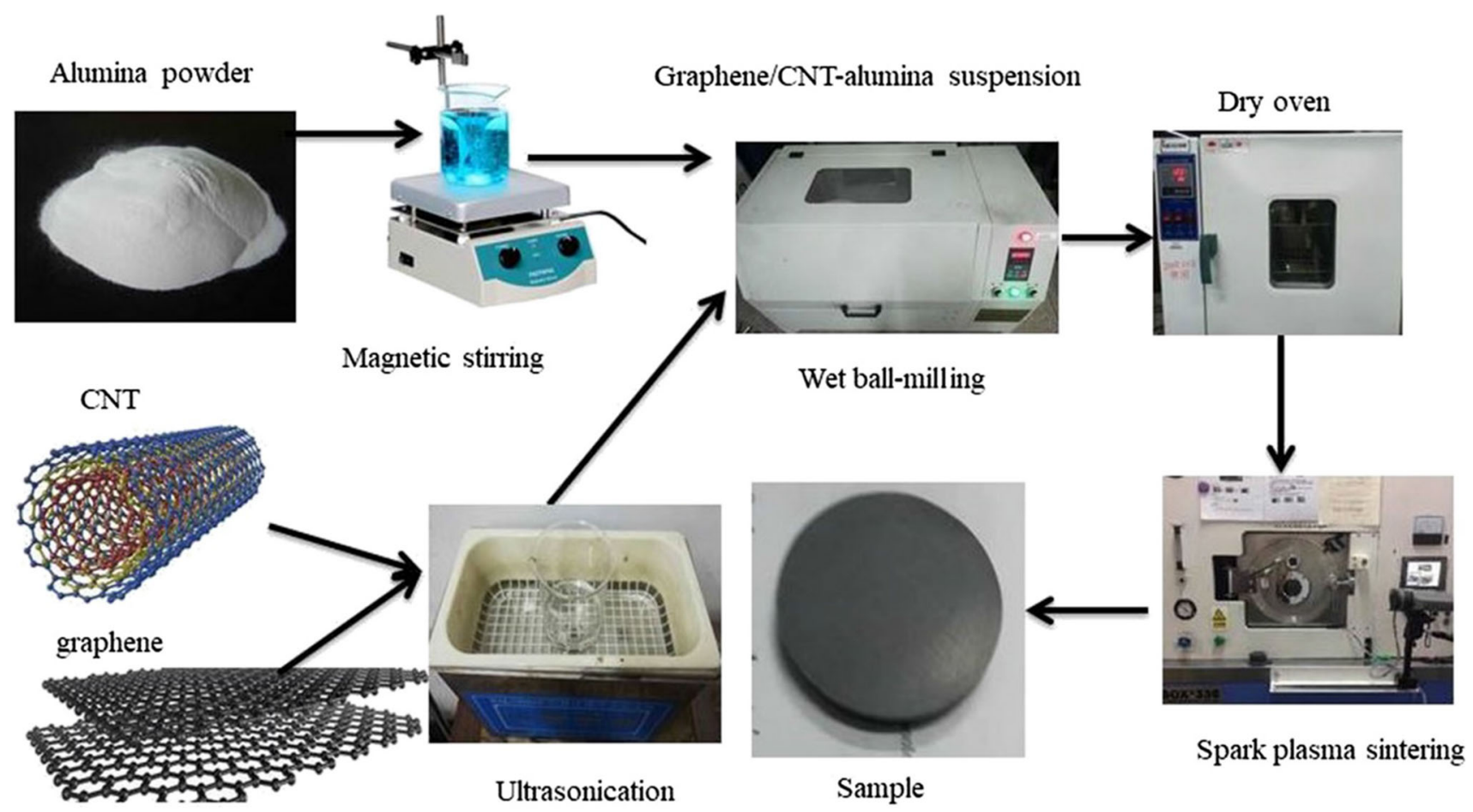

Figure 11 Graphene-CNTs/alumina nanocomposites preparation by Shah et al. adapted from Springer with permission [112].

properties for any aerospace materials and ceramics being brittle in nature requires reinforcement to enhance its brittle behaviour. CNTs are one such reinforcement which could be used to enhance the fracture toughness of the ceramics. Several literature studies have focused on the effect of CNTs on the mechanical properties of ceramics and it has been determined that appropriate CNTs compositions, densification techniques and homogenous distribution of CNTs onto the ceramic matrix are required to enhance the properties of the composites [31-33]. However, there have been also anomalies in mechanical properties noted by various researchers which highlights the importance of CNT/ceramic composition. Literatures on CNT composites with $\mathrm{SiC}, \mathrm{YSZ}$ and alumina with various compositions showed excellent properties at $1 \mathrm{wt} . \%$ MWCNT reinforcement [31-33]. Figure 12 illustrates the indentation on the surface (Fig. 12a) and fracture mechanisms like pull-out and bridging (Fig. 12b) on the alumina/MWCNTs surfaces which were dominating failure mechanisms. This was also reported in a previous work of MWCNTs/YSZ nanocomposites which have shown formation of pores with increase in MWCNTs due to agglomeration on the surfaces and a reduced heating effect on the sintered surfaces
[31]. Ghobadi et al. prepared alumina-based CNT composites using cold pressing technique and reported a flexural strength of $465 \pm 31 \mathrm{MPa}$ whereas Ramachandran et al. reported flexural strength of $515 \pm 33 \mathrm{MPa}$ using SPS [33, 121]. These results from the researchers prove that the mechanical properties depend on the fabrication technique and bulk density of the composites.

Table 7 reports various mechanical properties adapted from different investigations which use CNT reinforcement at different compositions to enhance the properties of the ceramics. As reported in Table 7, most studies reported the MWCNT reinforcement onto ceramics enhanced the mechanical properties to certain extend. Most of the studies indicated that mechanisms like fibre pull-out, fibre bridging and crack deflections on material surfaces due to the presence MWCNTs on the composites were responsible for the enhancement of the mechanical properties. In contrast, some show that the mechanical properties of the CNT-reinforced composites also depend on the densification techniques and porosity of the material. Arunkumar et al. reported increase in CNTs content resulted in increase in the porosity of the composites as there was a transition from open pores to closed pores as illustrated in Fig. 13. 
Table 6 Thermal properties of ceramic/CNT composites reported by various researchers

\begin{tabular}{|c|c|c|c|c|c|c|c|}
\hline Composite & Preparation technique & $\begin{array}{l}\text { Densification } \\
\text { Technique }\end{array}$ & CNT content & $\begin{array}{l}\text { Diffusivity } \\
\mathrm{mm} 2 / \mathrm{s}\end{array}$ & $\begin{array}{l}\text { Thermal } \\
\text { conductivity } \\
(\mathrm{W} / \mathrm{mK})\end{array}$ & $\begin{array}{l}\text { Heat capacity } \\
\mathrm{J} / \mathrm{gK}\end{array}$ & References \\
\hline $\begin{array}{c}\text { MWCNT/ } \\
\mathrm{Al}_{2} \mathrm{O}_{3}\end{array}$ & Powder processing & $\begin{array}{l}\text { Spark plasma } \\
\text { sintering at } \\
1500{ }^{\circ} \mathrm{C}\end{array}$ & $1 \mathrm{wt} \%$ & 8.77 & 29.62 & 0.87 & {$[115]$} \\
\hline $\begin{array}{c}\text { MWCNT/ } \\
\mathrm{Al}_{2} \mathrm{O}_{3}\end{array}$ & Powder processing & $\begin{array}{l}\text { Spark plasma } \\
\text { sintering }\end{array}$ & $\begin{array}{c}7.39 \mathrm{wt} \% \text { and } \\
19.10 \mathrm{wt} \%\end{array}$ & $\begin{array}{l}13.98 \text { at } \\
25^{\circ} \mathrm{C} \text { and } \\
5.24 \text { at } \\
25^{\circ} \mathrm{C}\end{array}$ & $\begin{array}{l}90.44 \text { at } 100{ }^{\circ} \mathrm{C} \\
\text { and } 36.77 \text { at } \\
100{ }^{\circ} \mathrm{C}\end{array}$ & $\begin{array}{l}2.09 \text { at } 60^{\circ} \mathrm{C} \\
\text { and } 3.31 \text { at } \\
60{ }^{\circ} \mathrm{C}\end{array}$ & {$[111]$} \\
\hline $\begin{array}{l}\mathrm{SWCNT} / \\
\mathrm{Al}_{2} \mathrm{O}_{3}\end{array}$ & Powder processing & $\begin{array}{l}\text { Spark plasma } \\
\text { sintering }\end{array}$ & $\begin{array}{l}10 \mathrm{vol} \% \text { and } \\
15 \mathrm{vol} \%\end{array}$ & - & 11.4 and 7.3 & - & [116] \\
\hline $\begin{array}{l}\text { MWCNT/ } \\
\text { TiN }\end{array}$ & Powder processing & $\begin{array}{l}\text { Spark plasma } \\
\text { sintering }\end{array}$ & $1 \mathrm{Wt} \%$ & $\begin{array}{l}3.25 \text { at } \\
375^{\circ} \mathrm{C}\end{array}$ & 14.75 at $375{ }^{\circ} \mathrm{C}$ & 0.9 at $375{ }^{\circ} \mathrm{C}$ & {$[117]$} \\
\hline $\begin{array}{l}\mathrm{MWCNT} / \\
\mathrm{SiO}_{2}\end{array}$ & Hot pressing & $\begin{array}{l}\text { Spark plasma } \\
\text { sintering }\end{array}$ & $\begin{array}{l}5 \text { vol. } \% \\
\quad \& 10 \text { vol. } \%\end{array}$ & - & $\begin{array}{l}3.48 \pm 0.01 \\
\text { and } \\
4.08 \pm 0.01\end{array}$ & - & {$[118]$} \\
\hline $\begin{array}{l}\mathrm{CNT}- \\
\text { graphene/ } \\
\mathrm{Al}_{2} \mathrm{O}_{3}\end{array}$ & Powder processing & $\begin{array}{l}\text { Spark plasma } \\
\text { sintering }\end{array}$ & $\begin{array}{l}0.4 \mathrm{Wt} \% \\
\text { graphene and } \\
1 \mathrm{Wt} \% \mathrm{CNT}\end{array}$ & 7.56 & 23.25 & $\begin{array}{l}1.0606 \text { and } \\
1.04691 \text { at } \\
300{ }^{\circ} \mathrm{C}\end{array}$ & [112] \\
\hline $\mathrm{C} / \mathrm{SiC}$ & $\begin{array}{l}\text { Laser-assisted } \\
\text { chemical vapour } \\
\text { infiltration (LA-CVI) }\end{array}$ & $\begin{array}{l}\text { Vacuum } \\
\text { impregnation }\end{array}$ & $0.5 \mathrm{Wt} \%$ & - & 150.42 & - & [92] \\
\hline $\begin{array}{c}\mathrm{ZrB}_{2}-20 \\
\mathrm{SiC}- \\
\mathrm{CNT}\end{array}$ & Powder processing & $\begin{array}{l}\text { Spark plasma } \\
\text { sintering }\end{array}$ & 10 vol $\%$ & $\begin{array}{l}0.240 \text { at } \\
50{ }^{\circ} \mathrm{C} \\
0.121 \text { at } \\
1200{ }^{\circ} \mathrm{C}\end{array}$ & $\begin{array}{l}61.8 \text { at } 50{ }^{\circ} \mathrm{C} \\
51.4 \text { at } 1200{ }^{\circ} \mathrm{C}\end{array}$ & $\begin{array}{l}0.485 \text { at } \\
50{ }^{\circ} \mathrm{C} \\
0.802 \text { at } \\
1200{ }^{\circ} \mathrm{C}\end{array}$ & [119] \\
\hline $\mathrm{ZrB}_{2}-\mathrm{CNT}$ & Powder processing & $\begin{array}{l}\text { Spark plasma } \\
\text { sintering }\end{array}$ & 10 vol $\%$ & $\begin{array}{c}0.204 \text { at } \\
50{ }^{\circ} \mathrm{C} \\
0.130 \text { at } \\
200{ }^{\circ} \mathrm{C}\end{array}$ & $\begin{array}{l}48.9 \text { at } 50{ }^{\circ} \mathrm{C} \\
46.6 \text { at } 1200^{\circ} \mathrm{C}\end{array}$ & $\begin{array}{l}0.415 \text { at } \\
50{ }^{\circ} \mathrm{C} \\
0.632 \text { at } \\
1200{ }^{\circ} \mathrm{C}\end{array}$ & {$[120]$} \\
\hline
\end{tabular}

However, increase in MWCNTs content could lead to reduced solid state diffusion which could inhibit the transition of open pores. This could result in reduction of bulk density which weakens the composites leading to poor mechanical properties [31]. This effect was also previously observed on the alumina/ MWCNTs composites sintered through SPS providing evidence of pores transition from open to closed at temperature of $1050{ }^{\circ} \mathrm{C}$ [122]. Though the concept of open and closed pores is provided in detail with only these two researchers there is a very low possibility that the drop in mechanical properties with increase in the MWCNTs content could be a mechanism for the reduction. On the other hand, it is feasible to state that the porosity mechanism could have an effect at high MWCNTs content but possibly would not be a governing mechanism.
Like mechanical properties, tribological behaviour also plays a crucial role in determining the service life of the structural materials in various applications [33]. Various reinforcements and coatings are being considered to reduce the friction and wear behaviour of the materials [42]. Ceramics-based composites have limited usage in contact-based applications such as bearings, valves and nozzles owing to its high frictional and wear behaviour [128]. Thus, there is a need for protective coatings and reinforcements to enhance the wear behaviour of the ceramic matrix composites $[42,75]$. CNTs are one of the major reinforcement materials in the wear applications owing to its failure mechanisms and lubricating behaviour [33]. Ramachandran et al. studied the wear behaviour of the alumina/MWCNTs composites under varying load and time and determined that wear depended 


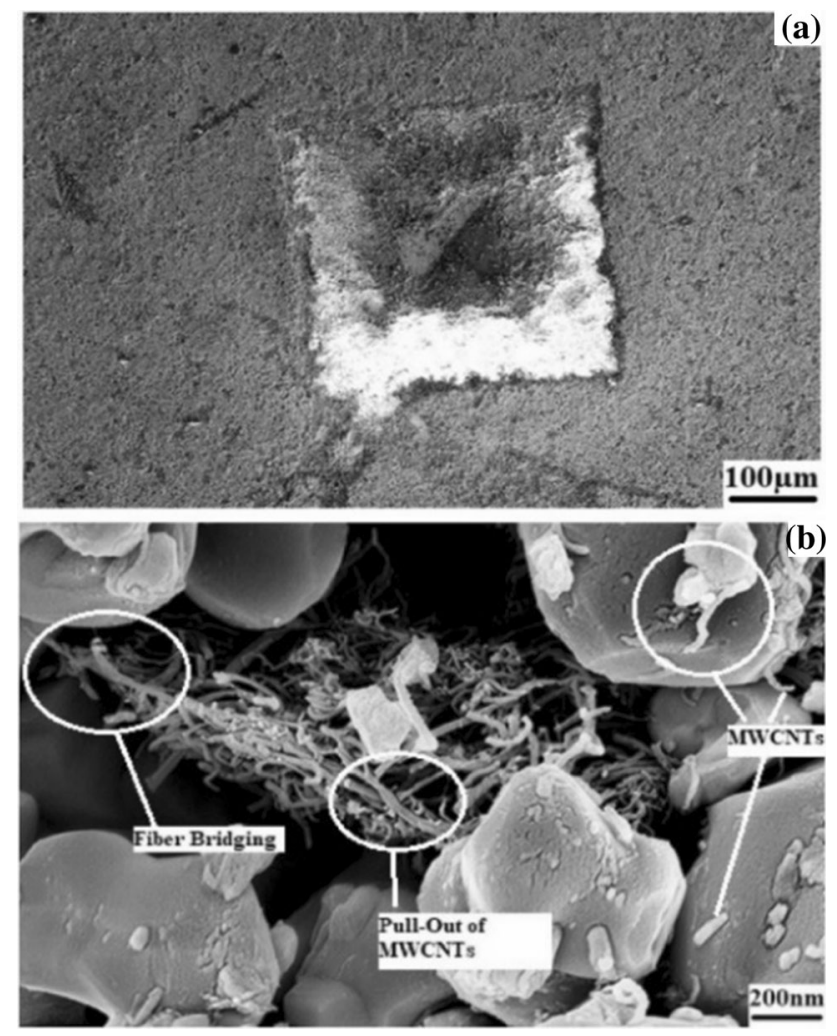

Figure 12 Surface indentation and fibre pull-out on $\mathrm{Al}_{2} \mathrm{O}_{3}$ / MWCNT nanocomposites adapted from K. Ramachandran et al. with permission [33].

on the MWCNTs content, time and load as shown in Fig. 14 [33]. However, Sharma et al. provided a contradictory report for the alumina/MWCNTs fabricated through SPS technique showing a lower wear rate at $3 \mathrm{vol} . \%$ MWCNT reinforcements compared to 1 vol.\% MWCNT which increased the wear rate at 5 vol.\% [46]. Other sources have provided evidence of reduction on the wear behaviour of the composites by reinforcing CNTs onto the ceramic bodies which were independent of densification techniques [75]. The lubricating behaviour of MWCNTs along with its different mechanisms including fibre pull-out and bridging on the surfaces enhanced the wear behaviour of the composites until its threshold limit. But with an increase in CNT content, increased agglomeration on the composite surfaces inhibited the wear behaviour [33]. Figure 15 adapted from Hazel et al. illustrates the microstructure of the composites reported that the failures on the wear run surfaces were due to the debriefs and scaling formed on the composites. The colour variation in the microstructure could have been due to the formation of mosaic like grains with varying grain sizes on the light
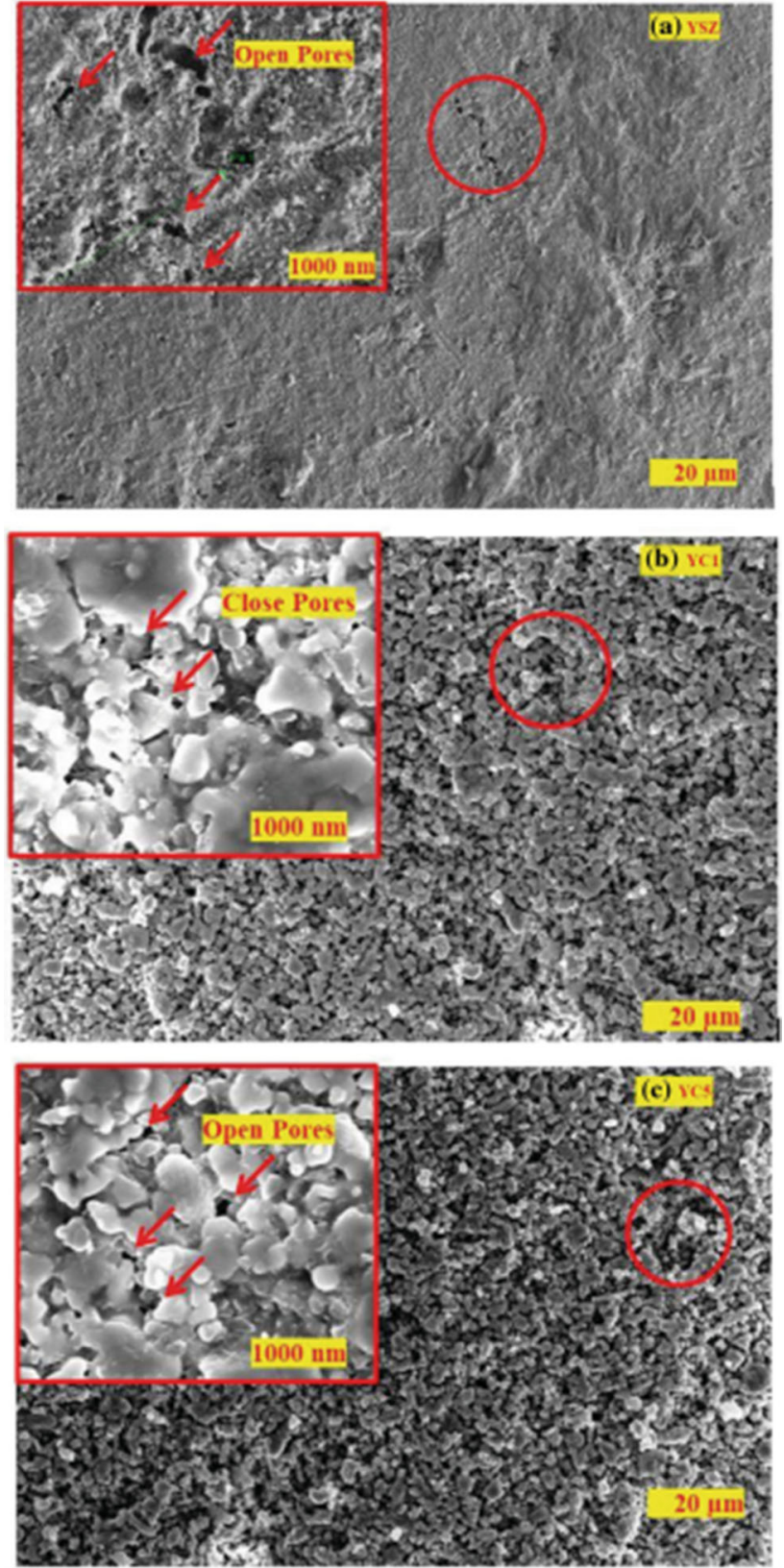

Figure 13 Open pores and closed pores transition with MWCNTs content on YSZ adapted from Arunkumar et al. with permission from corresponding author [31].

patched area which could avoid large wear whereas dark regions are stated to be mostly exposed with high amount of debriefs and scaling than the light region [114]. On the other hand, Ramachandran et al. stated that the load and sliding distance could have had higher impact on the wear behaviour as the materials temperature could increase inhibiting interfacing bonding between the CNT and alumina nanoparticles [33]. Few of the highlighted work in

\section{Springer}


Table 7 Mechanical properties of $\mathrm{CNT} /$ ceramics reported in various literatures

\begin{tabular}{|c|c|c|c|c|c|c|c|}
\hline Ceramics & $\begin{array}{l}\text { Preparation } \\
\text { techniques }\end{array}$ & $\begin{array}{l}\text { Densification } \\
\text { technique }\end{array}$ & $\begin{array}{l}\text { CNT } \\
\text { content }\end{array}$ & $\begin{array}{l}\text { Hardness } \\
(\mathrm{GPa})\end{array}$ & $\begin{array}{l}\text { Fracture toughness } \\
\left(\mathrm{MPa} \cdot \mathrm{m}^{0.5}\right)\end{array}$ & $\begin{array}{l}\text { Flexural } \\
\text { strength (MPa) }\end{array}$ & References \\
\hline $\mathrm{Al}_{2} \mathrm{O}_{3}$ & Colloidal route & $\begin{array}{l}\text { Spark plasma } \\
\text { sintering }\end{array}$ & 1 wt. $\%$ & $17.26 \pm 0.4$ & $\begin{array}{l}\text { Indentation } \\
5.6 \pm 0.3 \\
\text { SEVNB } 5.2 \pm 0.6\end{array}$ & $515 \pm 33$ & {$[33]$} \\
\hline $\mathrm{Al}_{2} \mathrm{O}_{3}$ & $\begin{array}{r}\text { Suspension } \\
\text { technique }\end{array}$ & $\begin{array}{l}\text { Isotropic cold } \\
\text { pressing }\end{array}$ & 1 vol. $\%$ & - & $\begin{array}{r}\text { Indentation } \\
4.2 \pm 0.2\end{array}$ & $465 \pm 31$ & {$[121]$} \\
\hline $\mathrm{Al}_{2} \mathrm{O}_{3}$ & Colloidal route & Hot pressing & 1 wt. $\%$ & - & $4.0 \pm 0.5$ & $536 \pm 44$ & {$[51]$} \\
\hline $\mathrm{Al}_{2} \mathrm{O}_{3}$ & Powder processing & $\begin{array}{l}\text { Spark plasma } \\
\text { sintering }\end{array}$ & 0.8 wt. $\%$ & - & 3.85 & - & {$[46]$} \\
\hline $\mathrm{Al}_{2} \mathrm{O}_{3}$ & Precursor technique & $\begin{array}{l}\text { Spark plasma } \\
\text { sintering }\end{array}$ & 2 wt. $\%$ & - & 3.6 & 315 & {$[123]$} \\
\hline $\begin{array}{l}\mathrm{Al}_{2} \mathrm{O}_{3}- \\
\text { Whisker } \\
\mathrm{SiC}\end{array}$ & Powder processing & Hot pressing & 1 wt. $\%$ & 20.59 & $3.8-4.5$ & $700 \pm 50$ & {$[124]$} \\
\hline $\mathrm{SiC}$ & Colloidal route & $\begin{array}{l}\text { Spark plasma } \\
\text { sintering }\end{array}$ & 15 wt. $\%$ & 8.81 & 10.21 & - & {$[32]$} \\
\hline $\mathrm{SiC}$ & $\begin{array}{l}\text { Powder } \\
\text { processing/tape } \\
\text { casting }\end{array}$ & Hot pressing & 0.5 wt. $\%$ & $23.8 \pm 2.5$ & $6.1 \pm 0.6$ & $755 \pm 106$ & {$[125]$} \\
\hline $\mathrm{SiC}$ & Powder processing & $\begin{array}{l}\text { Aqueous tape } \\
\text { casting }\end{array}$ & 0.5 wt. $\%$ & $19.77 \pm 2.5$ & $4.38 \pm 0.15$ & $706.7 \pm 16.9$ & {$[126]$} \\
\hline $\mathrm{Al}_{2} \mathrm{O}_{3}-\mathrm{SiC}$ & Colloidal route & Cold pressing & 2 wt. $\%$ & $22 \pm 2.0$ & $6.5 \pm 0.4$ & - & {$[56]$} \\
\hline $\mathrm{SiC}$ & Powder processing & $\begin{array}{l}\text { High pressure } \\
\text { reaction sintering }\end{array}$ & $3: 2$ ratio & $20 \pm 2.0$ & $6.8 \pm 0.8$ & - & {$[127]$} \\
\hline YSZ & Colloidal route & $\begin{array}{l}\text { Spark plasma } \\
\text { sintering }\end{array}$ & $1 \%$ & $12.96 \pm 0.3$ & $\begin{array}{l}\text { Indentation } \\
6.58 \pm 0.3 \\
\text { SEVNB } \\
5.22 \pm 0.3\end{array}$ & - & {$[31]$} \\
\hline YSZ & Powder processing & $\begin{array}{l}\text { Spark plasma } \\
\text { sintering }\end{array}$ & $5 \%$ & - & $15.2 \pm 0.4$ & - & {$[96]$} \\
\hline
\end{tabular}

this section explore the mechanical and tribological behaviour of MWCNTs-reinforced ceramic composites along with its failure mechanisms and quantity of CNTs being utilised for the composites. Although there has been constant enhancement in the properties with CNTs reinforcements, there is still a necessity to correlate the failure mechanisms with process parameters including densification time, temperature and testing environments which are yet to be developed in future along with few simulation tools.

\section{Applications of MWCNT/composites}

Nanocomposites are of great interest for various applications owing to their superior properties, surface to volume ratio and resistibility [33]. Currently, various research organisations such as NASA, JAXA and ISRO are actively working on the development of nanocomposites for various structural and aerospace applications [129]. Applications related to CNT-reinforced ceramic nanocomposites are discussed in detail in this section.

\section{Industrial \& automobile applications}

Nanocomposites have initiated a revolution of replacing the traditional alloys on the automobile composites [130, 131]. Steel-based components on automobiles provided high corrosion resistance and strength, but for high-performance vehicles, there is a need to reduce the weight/power ratio. Ceramics could act as possible replacement due to its lower weight to thrust ratio and high thermo-mechanical 


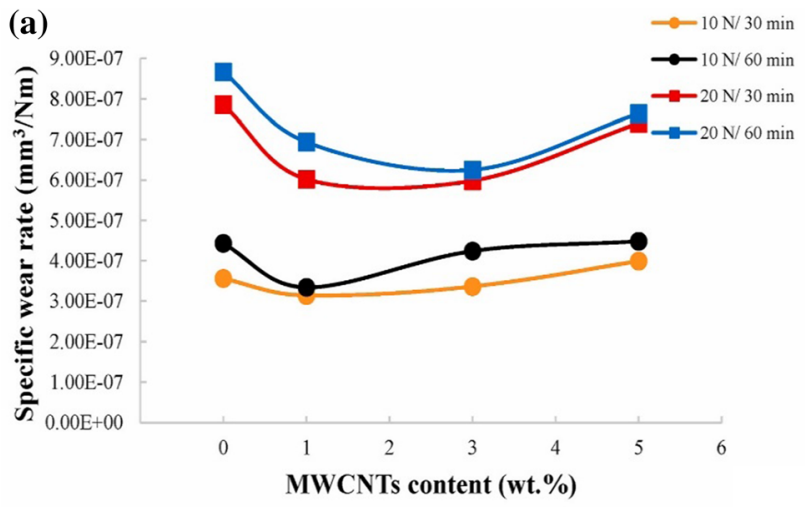

(b)

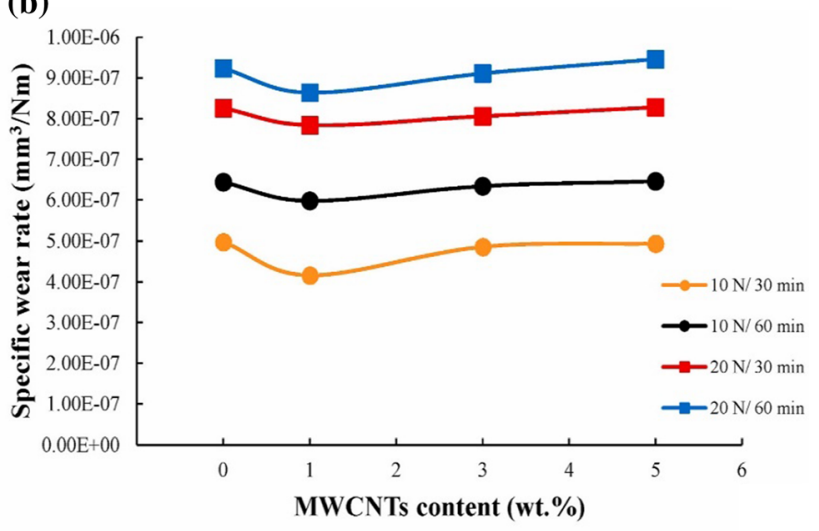

Figure 14 Wear behaviour of alumina/MWCNTs composites at varying sliding distance of $\mathbf{a} 100 \mathrm{~m}$ and $\mathbf{b} 200 \mathrm{~m}$ adapted from $\mathrm{K}$ Ramachandran et al. with permission [33].

behaviour. On the other hand, owing to its brittle behaviour, the life expectancy of ceramics is lower when compared to steel-based alloys [132]. Hence, using CNTs to reinforce ceramics enhances its fracture toughness to values greater than the highest- grade steel components. This allows the ceramics to act as possible replacement in automobile applications by providing with hardness, lightweight and high temperature capabilities. Reinforced ceramics have potential to be used in engine parts, brake discs, valves, cylinder liners, spark plug, sensors, isolators, filters and pistons-all are subjected to higher load and wear which could lead to deformation and wear and are examples where ceramic-based nanocomposites could be efficient [130, 131]. Along with the load bearing capabilities, wear is also an important factor in the automobile and industrialscale applications. CNT-based ceramic composites exhibit excellent wear-resistance behaviour by avoiding crack propagations and debriefs on the surfaces of the composites at various loads and temperatures [33]. CNT-based ceramic coatings have enhanced strength, wear resistance and higher fracture toughness [133]. Though, aluminium and its alloys are extremely popular in automobile applications for inner surfacing and ducting. Nowadays, aluminium-based metal matrix with ceramic reinforcements has also created new roles in automotive materials [130, 131]. Nayim et al. examined stir cased aluminium matrix composite reinforced with CNTs / $\mathrm{TiC}$ and reported a reduction in the density and increase in hardness due to the volatile nature of reinforcing material [134]. Though reinforcement of metals provided high strength and better properties, few articles reported low scale corrosive nature on the metal matrix composites which could be a concern for researchers. Therefore, there is a need for ceramics such as alumina, zirconia, $\mathrm{SiC}$ which are highly chemically inert and have reduced density

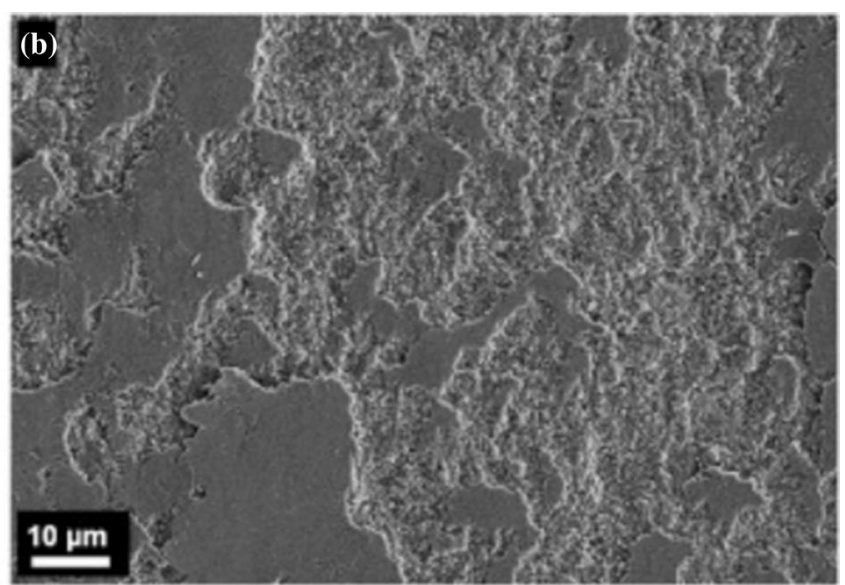

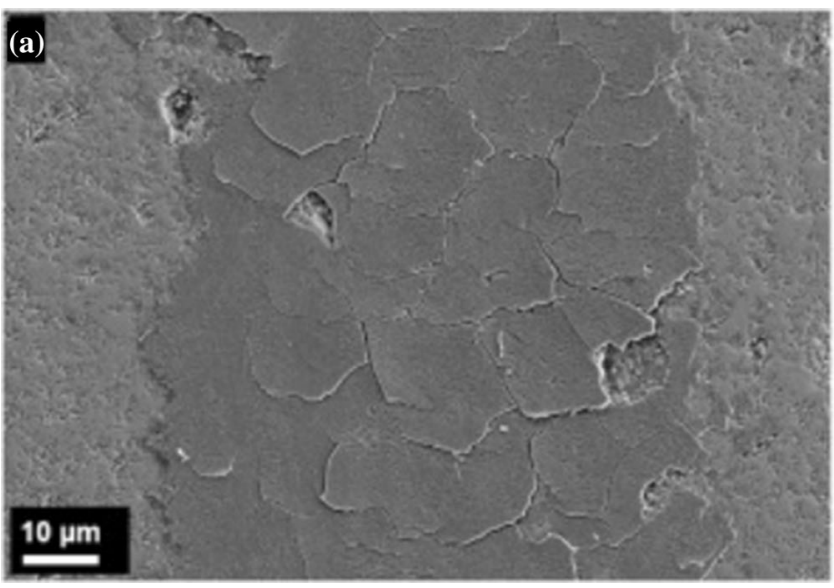

Figure 15 Wear topography of alumina with 10 vol.\% CNTs adapted from Hazel et al. with permission [114]. 
than the metal matrix composites are preferred. Leonov et al. fabricated alumina reinforced by MWCNTs through SPS and determined increase in fracture toughness of $4.93 \mathrm{MPa} \cdot \mathrm{m}^{0.5}$ and microhardness of $23.26 \mathrm{GPa}$ [135]. Likewise, reinforcing $\mathrm{SiC}$ which is generally non-conductive with 6 vol.\% MWCNTs enhanced electrical conductivity of the resulting composites enhanced its use in sensors, heat exchangers and automotive parts [136].

\section{Aerospace applications}

In recent decades, the aerospace industry has enjoyed rapid growth and in turn forces innovation in new materials. The possibility of combining desired material properties using nanocomposites has many potential applications in the aerospace industry. For example, ceramic materials have significant advantages in high-temperature applications. Various ceramics have been studied for its suitability in the thermal barrier coatings, structural areas and as reinforcements [32, 130, 131]. However, due to the lower fracture toughness and unable to satisfy required strength, ceramics require a potential reinforcement for its utilisation in aerospace industries. CNT reinforcements onto the ceramics could lead to improvement in mechanical and thermal properties of the composites along with satisfying high strength to weight ratio and fracture toughness which are crucial for the aerospace applications. Apart from structural strength, CNTs have potential to act as radiation shields for space vehicles [137]. Various research has been carried out for by researchers to determine the suitability of nanomaterials for radiation shielding including galactic cosmic radiation, solar particle events and neutron generated from interaction of solar and cosmic radiations [138]. Li et al. fabricated polydimethylsiloxane (PDMS)/ SWCNTs through curing technique under $80^{\circ} \mathrm{C}$ for proton radiation shielding and reported that under $105 \mathrm{MeV}$, the PDMS/SWCNT has shown enhanced proton stopping properties and was lighter in weight compared to PDMS and aluminium metal [139]. Likewise, CNT/polymer composites have also shown enhanced electromagnetic interference compared to polymer under same conditions [140]. The aerospace industry is classified into many categories such as commercial aircraft, unmanned aerial vehicle (UAV), rotorcraft, military aircraft and spacecraft (or) space shuttle as illustrated in Fig. 16. Despite this often-disparate categories, general problems includes weight, lightning strikes, icing, electromagnetic interference shielding, stealth applications and hypersonic vehicle problems such as air resistance, high temperature capabilities and structural failure [141]. In space propulsion, aircraft are directly exposed to high-intensity ionising radiation along with exposure to debris formed due to thermal cycling and micrometeorites [142]. The aerospace vehicles are also subjected to various conditions involving moisture variations and extreme temperatures which require effective solutions including materials to overcome these problems [143]. CNTbased ceramic nanocomposites have excellent future in the aerospace applications which were studied by Ames Research Centre and Johnson Space Centre of NASA which have conducted investigations on thermal radiation and impact protective systems using CNT-reinforced materials [144].

Icing is a major concern in the field of aerospace as water droplets on the surfaces are supercooled and affect the outer surface components of the aircrafts including compressors which could damage the lift and angles of attacks in the fixed wings aircrafts. Icing also has a huge impact on the propulsion efficiency due to the increase in drag value [145]. Peck et al. investigated icing problems in rotor aircraft and stated ice adhesion results in vibrations of rotor blades that can lead to forced landings along with blurred visions to the pilots and unreliable instrumental readings [146]. To overcome icing issues, there are few techniques including anti-icing coatings and thermal insulators which could be employed on the surfaces. However, adding in a thermal insulator could lead to increase in weight which could reduce the efficiency of the aircraft. Chu et al. developed selfheating CNT-reinforced composites which provided excellent electrical heating at ambient temperature [147]. MWCNTs-based thin and transparent films were developed by Yoon et al. for de-icing applications [148]. These CNTs-based web laminated acted as electrothermal heating for the anti-icing where the structure of web is aligned perfectly with negligible weight gain. The web structure could produce uniform heating with less energy consumption [149]. These coatings provided protection against icing edges and enhanced barrier resistance on the surfaces without compromising the thrust to weight ratio. Like icing, nullifying lightning strikes are a big challenge to every aircraft with statistical data 


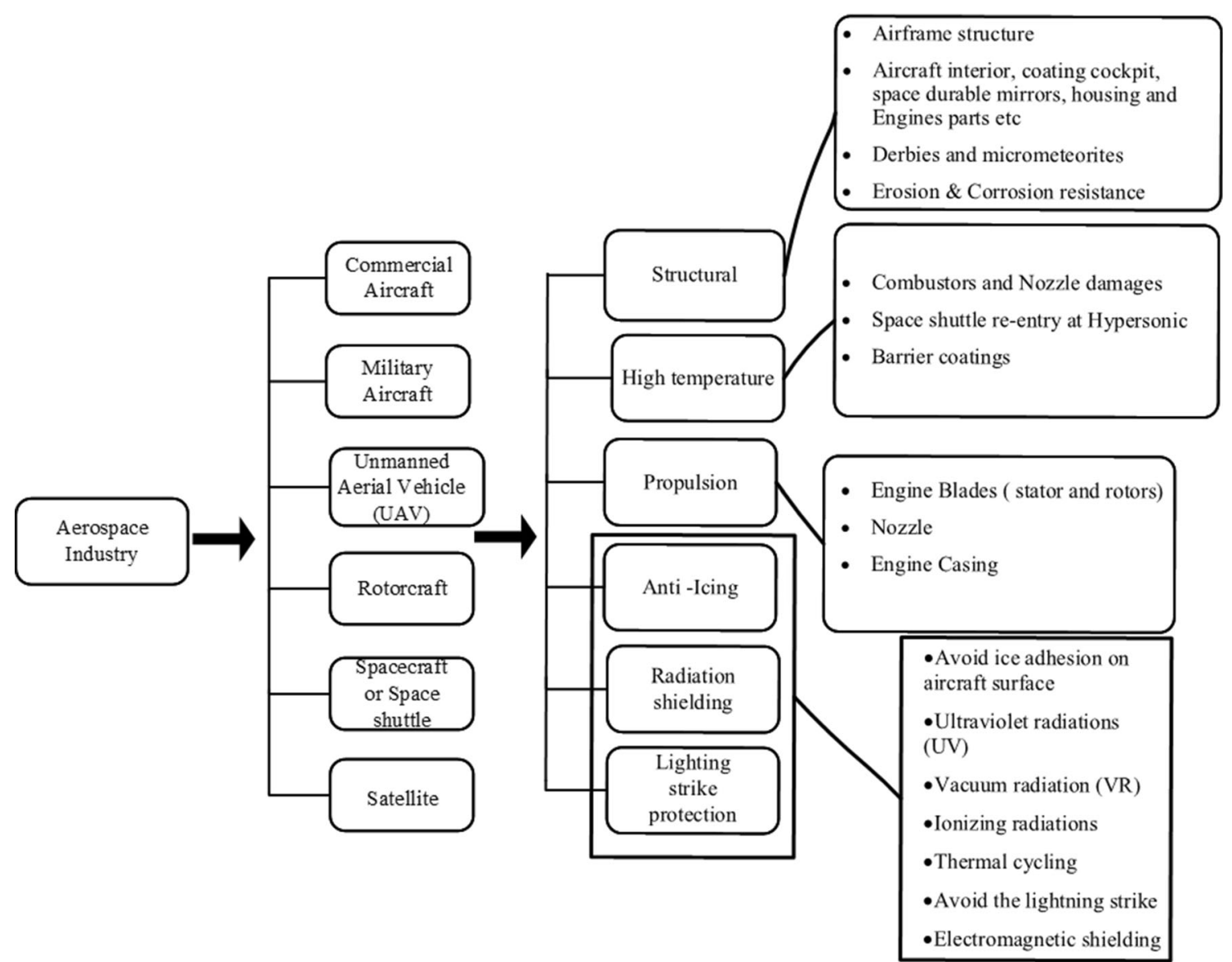

Figure 16 Schematics of classification of aerospace industry and its major concerns.

reporting most of aircrafts are subjected to lighting strike for 1000-10,000 h [150]. Lightning strikes on aircraft typically occur at an altitude of 5000-15,000 ft with a power of $200,000 \mathrm{~A}$ and heat generated close to $30,000{ }^{\circ} \mathrm{C}$ and impact force of 500 psi [144]. Lightning strikes can lead to damage, melting or burning of airframes. Conventional airframes are made of aluminium and its alloys which are highly conductive and reactive towards lighting strikes. Therefore, these materials tend to provide a threat towards the flying of the aircraft in the lighting climate. So, researchers have focused to form structural materials which can replace the aluminium-based alloys. Researchers have come across materials like fibre-reinforced polymers (FRP) which are unable to conduct high electrical current and electromagnetic force sufficiently during lighting which results to aircraft structural failures and electromagnetic waves interfere which may affect the communications and electronics devices in the aircraft. So, it is necessary to protect against lightning strike to prevent both lightning current and EMI phenomena. Recent studies conducted on CNT-based composites show that they can offer protection from lightning strikes. It reported advanced materials like polymer-based composites and SWCNTs could be utilised to improve lightning protection and electromagnetic interference resistance (EMI). CNTs and its carbonaceous structures-based composites could support the aerospace industry with superior shielding effectiveness and high specific surface area due to its high aspect ratios. Also owing to the high vaporisation rate of CNTs-based composites compared to metals, it is said that the material could withstand higher EM shielding and lightings [151]. However, there are still more studies required to understand a way to collaborate the lightning strike protection along with weight of the materials.

Weight of aerospace structures is a challenge towards the researchers working on the aerospace 
industries as it has impact on the efficiency and emissions of aircrafts. Generally, aircraft are designed in a way to reduce the total weight. However till date, there is no stand-out material which can withstand the extreme thermal strain and low weight requirements in aircraft engines [152]. Currently, Ni-based superalloys are utilised in turbine areas owing to its high temperature stability and thermo-mechanical properties at $800{ }^{\circ} \mathrm{C}$ with help of thermal barrier coatings [153]. So, there is a need of materials which can reduce and enhance the temperature capabilities of the turbines to increase the efficiency of the composites [154]. CNT-reinforced ceramics and CMCs are deemed to be a potential replacement in such areas and studies have been carried out to verify its suitability. Companies like Rolls Royce have initiated the use of the CMCs (oxide and non-oxide) in their stator parts. Though owing to its reaction with the water vapour, the service life of the CMCs is affected. As CNTs are inert to the water environment, the use of CNT-based composites could be utilised as a replacement. A simulation study by $\mathrm{O}^{\prime}$ Donnell et al. reported that by replacing aluminium in different commercial aircraft including Boeing 747-400, Boeing 757-200, Airbus A320 and Embraer E145 with CNTreinforced polymers could lead to $14 \%$ weight reduction, resulting in $13.2 \%$ range increase and $9.8 \%$ reduction in fuel consumption [155]. Further study by Gohardani et al. to replace the copper wiring by CNT-polymer-based composite wiring could lead to weight reduction by up to $69 \%$ [144]. These reports by researchers indicate that there is a constant need for developing the structural material in the area of the aircrafts and aerospace applications. The need for ultra-high-temperature ceramics (UHTCs) for hypersonic vehicles has been an important driving force in the field as hypersonic flight which involves high aerodynamic forces and extreme heat flux generated by temperatures of $\sim 2400{ }^{\circ} \mathrm{C}$. These UHTCs are designed to overcome thermo-mechanical problems occurring on the surfaces of the vehicle [143]. Currently, materials such as $\mathrm{Hf}, \mathrm{Zr}$ and other rareearth-based ceramics and composites have been studied as UHTCs owing to their higher temperature resistance and extreme heat flux [156, 157]. Although there have been studies describing the need for ceramic-based composites for high-temperature applications, there is still a fundamental requirement for enhancing the thermo-mechanical capabilities of ceramics in UHTCs. Though most ceramics have good thermal resistance, ceramic/CNT composites (thermal conductivity $\sim 3000 \mathrm{~W} / \mathrm{mK}$ ) provide enhanced resistance towards thermal damage with improvement in the thermal behaviours of the composites [158]. Numerous research articles have been published on reinforcing different UHTCs with CNTs to enhance the thermal behaviour and fracture toughness of the materials [158, 159]. Upada et al. utilised CNTs as reinforcement and a coating for aerospace engine components which enhanced their corrosive resistance and service life [160].

Like the structural needs, stealth is one of the major requirements in the aerospace industry especially for military applications. Emerging additive manufacturing of aerospace components and high specific strength of the CNTs make them one of the key elements for improving the mechanical properties. Owing to the absorption structure of CNTs, they are highly capable of absorption EM waves and $X$ band frequencies and could enhance the stealth characteristics of the aircraft. Kim et al. studied the absorption rate of CNTs-based sandwich composite and aluminium and reported that CNT-based sandwich absorbed $90 \%$ of the EM waves which was 3 times higher than aluminium [161]. Along with these issues in the aerospace, there is also a constant need to enhance the efficiency of aircraft turbine engines. This could be achieved by enhancing the gas inlet temperature. However, increasing the gas turbine inlet temperature could lead to melting of Ni-superalloys which is already supported by thermal barrier coatings. Therefore, there is a need for high-temperature material which can reduce the weight and serve as replacement in turbine blades. Ceramics matrix composites (CMCs) are currently being research for its usage in turbine blades [162]. However, due to their reaction with water vapour, there is a need of new coating techniques which could enhance protection under various environments [163]. Many researchers approach this with a multilayer coating consisting of a bond layer, intermediate layer and top layer [164]. Studies have been also conducted to understand the suitability of ceramic/CNT composites as bond layer materials and thermal barrier coatings [133]. Goyal et al. studied the behaviour of CNT-reinforced $\mathrm{Cr}_{2} \mathrm{O}_{3}$ composites coatings for a thermal power plant barrier at a temperature of $900{ }^{\circ} \mathrm{C}$. The CNT composition ranged from 1 to $8 \%$ and it was determined that with increase in CNT content, the corrosion resistance enhanced with 
reduced weight gain [165]. Furthermore, the substrates were also modified to enhance the fracture toughness and hardness of the composites. Choudhary et al. found that a modified a Ni-based alloy with $1 \mathrm{wt}$ \% CNT reinforcement through a selective laser melting technique enhanced the elastic modulus up to 2.7 times compared to a normal Ni-based alloy. The plasma coating of lanthanum zirconate on $\mathrm{Ni}$ / CNT composites showed suppression thermally grown oxide growth at $1800{ }^{\circ} \mathrm{C}$ which was stated to be $600-800{ }^{\circ} \mathrm{C}$ higher than current aero-turbine engines [166]. Though there has been various research to determine the suitable materials for the environmental and thermal barrier coatings including rare earth silicates and zirconates for top layer coatings. There are only limited studies to determine the adhesion behaviour of the bond layer with the substrates including Ni-based superalloys and ceramic matrix composites. Further, there is also a lot of research required to establish a definite correlation between the quantity of MWCNTs reinforcements essential for improving the mechanical and thermal properties of the ceramic nanocomposites with the physical parameters including fabrication techniques factors such as pressure and temperatures for preparing high-quality aerospace applications and other engineering sectors.

\section{Summary and future work}

The present review on the MWCNT-reinforced ceramic composites describes various processing and densification techniques developed to enhance the properties of the CNT-reinforced ceramic composites. These newly developed techniques have provided better and more consistent distribution of MWCNTs within the ceramic matrix leading to improved mechanical and thermal properties. However, there is still a need to improve the fabrication and processing techniques to produce highly distributed MWCNTs onto the ceramics composites which could enhance the mechanical properties and fracture toughness.

By reviewing the fabrication and processing techniques associated with MWCNTs/ceramics nanocomposite fabrications, it can be stated that the: (1) dispersion of MWCNTs onto the matrix, (2)
Interfacing bonding between MWCNTs and ceramics and (3) Novel techniques to prevent damage of CNTs are critical issues which are to be addressed to fabricate highly dense and distributed nanocomposites. Furthermore, the investigation of the thermo-mechanical properties of MWCNT/ceramic composites indicated the necessity of novel fabrication method which utilises sufficient MWCNTs content for various applications with toughness enhancing mechanisms like fibre pull-out, crack and fire bridging and crack deflections. Though it could be stated the future developed novel method could enhance the toughening mechanisms, there is still a need to establish relationship between various structural parameters with toughening mechanisms to attain high order relationship between the CNTs and composites. Also, there is a need to determine the amount of MWCNTs required to enhance and further an optimal technique is necessary to understand the design of MWCNTsreinforced ceramic composites. The additive manufacturing sector could be game changer in the field of fabricating MWCNTs-based ceramic composites. However, with current achievements and growth in the additive manufacturing sector it would be question of time and optimisation for developing such techniques.

On the other hand, the immediate need of materials in the field of aerospace where CNT-based composites could be utilised has been discussed in detail along with various applications of CNT-reinforced ceramics. Though CNT-reinforced ceramics have various potential applications in aerospace industries. There is still a gap to understand the requirements of aerospace industries where the composites based on CNTs could fill in. Further, the gap in understanding the need of aerospace materials which could enhance the efficiency along with structural improvements is still occurring research and understanding the requirements is still closing up, it can be said that the CNT-ceramic composites could act as potential replacements in the industry with further research.

\section{Acknowledgements}

One of the authors Karthikeyan Ramachandran would like to acknowledge Kingston University, London, for funding his Ph.D. research. 


\section{Funding}

The authors declare that they haven't received any funding towards this work.

\section{Declarations}

Conflict of interest The authors declare that they do not have any known competing financial or personal relationship that could have appeared to influence the work in the paper.

Open Access This article is licensed under a Creative Commons Attribution 4.0 International License, which permits use, sharing, adaptation, distribution and reproduction in any medium or format, as long as you give appropriate credit to the original author(s) and the source, provide a link to the Creative Commons licence, and indicate if changes were made. The images or other third party material in this article are included in the article's Creative Commons licence, unless indicated otherwise in a credit line to the material. If material is not included in the article's Creative Commons licence and your intended use is not permitted by statutory regulation or exceeds the permitted use, you will need to obtain permission directly from the copyright holder. To view a copy of this licence, visit http://creativecommons.org/licen ses/by/4.0/.

\section{References}

[1] Gruere GP (2012) Implications of nanotechnology growth in food and agriculture in OECD countries. Food Policy 37(2):191-198

[2] NSTC (2005) National nanotechnology initiative, research and development leading to a revolution in technology and industry. National Science and Technology Council, USA

[3] Mourdikoudis S, Pallares RM, Thanh NT (2018) Characterization techniques for nanoparticles: comparison and complementarity upon studying nanoparticle properties. Nanoscale 10(27):12871-12934

[4] Iijima S (1991) Helical microtubules of graphitic carbon. Nature 354:56-58

[5] Polizu S, Savadoga O, Poulin P, Yuahia L (2006) Applications of carbon nanotubes-based biomaterials in biomedical nanotechnology. J Nanosci Nanotechnol 6(7):1883-1904
[6] He H, Pham-Huy LA, Dramou P, Xiao D, Zuo P, PhamHuy C (2013) Carbon nanotubes: applications in pharmacy and medicine. Biomed Res Int 2013:1-12

[7] Ajayan PM (1999) Nanotubes from carbon. Chem Rev 99(7):1787-1799

[8] Harris PJF (2009) Carbon nanotube science: synthesis, properties and applications. Cambridge University Press, Cambridge

[9] Bachtold A, Hadley P, Nakanishi T, Dekker C (2001) Logic circuits with carbon nanotube transistors. Science 294(5545):1317-1320

[10] Dillon A, Jones K, Bekkendahl T, Kiang C, Bethune D, Huben M (1997) Storage of hydrogen in single-walled carbon nanotubes. Nature 386:377-379

[11] Collins P, Arnold M, Avouris P (2001) Engineering carbon nanotubes and nanotube circuits using electrical breakdown. Science 292:706-709

[12] Abrahamson J, Wiles PG, Rhoades BL (1999) Structure of carbon fibres found on carbon arc anodes. Carbon 37(11):1873-1874

[13] Dresselhaus MS, Dresselhaus G, Jorio A (2004) Unusual properties and structure of carbon nanotubes. Annu Rev Mater Res 34:247-278

[14] Arunkumar T, Karthikeyan R, Subramani RR, Viswanathan K, Anish M (2020) Synthesis and characterisation of multiwalled carbon nanotubes (MWCNTs). Int J Ambient Energy 41(4):452-456

[15] Iijima S, Ajayan PM, Ichihashi T (1992) Growth model for carbon nanotubes. Phys Rev Lett 69(21):3100-3103

[16] Coquay P, Grave ED, Peigney A, Vandenberghe RE, Laurent C (2002) Carbon nanotubes by a CVD method Part. I: synthesis and characterization of the $(\mathrm{Mg}, \mathrm{Fe}) \mathrm{O}$ catalysts. J Phys Chem B 106(51):13186-13198

[17] Lin J, Yang Y, Zhang H, Su B, Yang Y (2020) Optimization of CNTs growth on TiB2-based composite powders by CVD with $\mathrm{Fe}$ as catalyst. Ceram Int 46(3):3837-3843

[18] Mazumder S, Sarkar N, Park J, Han I, Kim I (2016) Carbon nanotubes-porous ceramic composite by in situ CCVD growth of CNTs. Mater Chem Phys 171:247-251

[19] Szabo A, Perri C, Csato A, Giordano G, Vuono D, Nagy JB (2010) Synthesis methods of carbon nanotubes and related materials. Materials 3(5):3092-3140

[20] Khan MU, Reddy KR, Snguanwongchai T, Hague E, Gomes VG (2016) Polymer brush synthesis on surface modified carbon nanotubes via in situ emulsion polymerization. Colloid Polym Sci 294:1599-1610

[21] Zhao G, Liu H, Du X, Zhou H, Pan Z, Mai Y, Jia Y, Yan W (2020) Flame synthesis of carbon nanotubes on glass fibre fabrics and their enhancement in electrical and thermal properties of glass fibre/epoxy composites. Compos B Eng 
198:108249. https://doi.org/10.1016/j.compositesb.2020. 108249

[22] Zhao G, Lou H, Du X, Zhou H, Mai Y, Jia Y, Yan W (2021) Glass fibres coated with flame synthesised carbon nanotubes to enhance interface properties. Compos Commun 24:100623. https://doi.org/10.1016/j.coco.2020.100623

[23] Height M, Howard J, Tester J, Sande J (2004) Flame synthesis of single-walled carbon nanotubes. Carbon 42:2295-2307

[24] Zhuo C, Hall B, Richter H, Levendis Y (2010) Synthesis of carbon nanotubes by sequential pyrolysis and combustion of polyethylene. Carbon 48:4024-4034

[25] Chung D-H, Lin T-H, Hou S-S (2010) Flame synthesis of carbon nano-onions enhanced by acoustic modulation. Nanotechnology 21:435604-435615

[26] Nikkanen J, Harju M, Jarn M, Linden J, Rintala J, Messing M, Saarivirta E, Saarinen T, Kanera T, Honkanen M, Aromaa M, Levanen E, Pettersson M, Makela J, Deppert K, Mantyla T (2014) Synthesis of carbon nanotubes on FexOy doped A12O3-ZrO2 nanopowder. Powder Technol 206:106-112

[27] Radhamani A, Lau H, Ramakrishna S (2018) CNT-reinforced metal and steel nanocomposites: a comprehensive assessment of progress and future directions. Compos A Appl Sci Manuf 114:170-187

[28] Estili M, Kwon H, Kawasaki A, Cho S, Takagi K, Kikuchi K, Kawai M (2010) Multiwalled carbon nanotube-reinforced ceramic matrix composites as a promising structural material. J Nucl Mater 398(1-3):244-245

[29] Ramachandran K, Carmine Z, Yoshida K, Tsunoura T, Jayaseelan D (2021) Experimental investigation and mathematical modelling of water vapour corrosion of Ti3SiC2 and Ti2AlC ceramics and their mechanical behaviour. J Eur Ceram Soc 41(9):4761-4773

[30] Ramachandran K, Leelavinodhan S, Antao C, Copti A, Mauricio C, Jyothi Y, Jayaseelan D (2021) Analysis of failure mechanisms of oxide-oxide ceramic matrix composites. J Eur Ceram Soc. https://doi.org/10.1016/j.jeurcera msoc.2021.11.020

[31] Arunkumar T, Anand G, Subbiah R, Karthikeyan R, Jeevahan J (2021) Effect of multiwalled carbon nanotubes on improvement of fracture toughness of spark-plasma-sintered yttria-stabilized zirconia nanocomposites. J Mater Eng Perform 30:3925-3933

[32] Arunkumar T, Karthikeyan R, Subramani RR, Anish M, Jayaraman T, Boddula R, Jagannathan M (2020) Effect of MWCNTs on improvement of fracture toughness of spark plasma sintered $\mathrm{SiC}$ nano-composites. Curr Anal Chem $16(1): 1-8$
[33] Ramachandran K, Subramani R, Arunkumar T, Boopalan V (2021) Mechanical and thermal properties of spark plasma sintered Alumina-MWCNTs nanocomposites prepared via improvised colloidal route. Mater Chem Phys 272:125034. https://doi.org/10.1016/j.matchemphys.2021.125034

[34] Palaci I, Fedrigo S, Brune H, Klinke C, Chen M, Riedo E (2005) Radial elasticity of multiwalled carbon nanotubes. Phys Rev Lett 94(17):175502. https://doi.org/10.1103/Phy sRevLett.94.175502

[35] Cho J, Boccaccini AR, Shaffer MSP (2009) Ceramic matrix composites containing carbon nanotubes. J Mater Sci 44:1934-1951. https://doi.org/10.1007/s10853-009-3262-9

[36] Bezzi G, Celotti G, Landi E, Torretta TL, Sopyan I, Tampieri A (2003) A novel sol-gel technique for hydroxyapatite preparation. Mater Chem Phys 78(3):816-824

[37] Jayaseelan D, Nishikawa T, Awaji H, Gnanam FD (1998) Pressureless sintering of sol-gel derived alumina-zirconia composites. Mater Sci Eng A 256(1-2):265-270

[38] Chan KF, Zaid MHM, Mamat MS, Liza S, Tanemura M, Yaakob Y (2021) Recent developments in carbon nanotubes-reinforced ceramic matrix composites: a review on dispersion and densification techniques. Curr ComputAided Drug Des 11(457):1-37

[39] Almeida VO, Balzaretti NM, Costa TMH, Machado GB, Gallas MR (2013) Surfactants for CNTs dispersion in zirconia-based ceramic matrix by sol-gel method. J Sol-Gel Sci Technol 65:143-149

[40] Ghozatloo A, Rashidi A, Shariaty-Niasar M (2014) Effects of surface modification on the dispersion and thermal conductivity of CNT/water nanofluids. Int Commun Heat Mass Transf 54:1-7

[41] Silva P, Almeida V, Machado G, Benvenutti E, Costa T, Gallas M (2012) Surfactant-based dispersant for multiwall carbon nanotubes to prepare ceramic composites by a sol-gel method. Langmuir 28(2):1447-1452

[42] Lopez A, Urena A, Rams J (2011) Wear resistant coatings: silica sol-gel reinforced with carbon nanotubes. Thin Solid Films 519(22):7904-7910

[43] Gao B, Peng C, Chen GZ, Puma GL (2008) Photo-electrocatalysis enhancement on carbon nanotubes/titanium dioxide (CNTs/TiO2) composite prepared by a novel surfactant wrapping sol-gel method. Appl Catal B 85(1-2):17-23

[44] Boulerouah A, Longuemart S, Hus P, Sahraoui AH (2012) Thermal transport investigation in a $\mathrm{CNTs} /$ solid matrix composite. J Phys D Appl Phys 46(05):055302. https://doi. org/10.1088/0022-3727/46/5/055302

[45] Tatami J, Katashima T, Komeya K, Meguro T, Wakihara T (2005) Electrically conductive CNT-dispersed silicon nitride ceramics. J Am Ceram Soc 88(10):2889-2893 
[46] Sharma N, Syed A, Ray B, Yadav S, Biswas K (2019) Alumina-MWCNT composites: microstructural characterization and mechanical properties. J Asian Ceram Soc $7(1): 1-19$

[47] Gojny F, Nastalczyk J, Roslaniec Z, Schulte K (2003) Surface modified multi-walled carbon nanotubes in CNT/ epoxy-composites. Chem Phys Lett 370(5-6):820-824

[48] Boccaccini AR, Cho J, Roether J, Thomas BJ, Minay EJ, Shaffer MS (2006) Electrophoretic deposition of carbon nanotubes. Carbon 44(15):3149-3160

[49] Arvanitelis C, Jayaseelan D, Cho J, Boccaccini A (2008) Carbon nanotube- $\mathrm{SiO} 2$ composites by colloidal processing. Adv Appl Ceram 107(3):155-158

[50] Garmendia N, Santazruz I, Moreno R, Obieta I (2010) Zirconia-MWCNT nanocomposites for biomedical applications obtained by colloidal processing. J Mater Sci Mater Med 21(5):1445-1451

[51] Sun J, Gao L, Jin X (2005) Reinforcement of alumina matrix with multi-walled carbon nanotubes. Ceram Int 31(6):893-896

[52] Sun J, Gao L, Li W (2002) Colloidal processing of carbon nanotube/alumina composites. Chem Mater 14(12):5169-5172

[53] Inam F, Heaton A, Brown P, Peijs T, Reece M (2014) Effects of dispersion surfactants on the properties of ceramic-carbon nanotube (CNT) nanocomposites. Ceram Int 40(1):511-516

[54] Novak S, Ivekovic A (2013) SiC-CNT composite prepared by electrophoretic codeposition and the polymer infiltration and pyrolysis process. J Phys Chem B 117(6):1680-1685

[55] Garmendia N, Santacruz I, Moreno R, Obieta I (2009) Slip casting of nanozirconia/MWCNT composites using a heterocoagulation process. $\mathrm{J}$ Eur Ceram Soc 29(10):1939-1945

[56] Ahmad I, Ahmed S, Subhani T, Saeed K, Islam M, Wang N, Zhu Y (2016) Synergic influence of MWCNTs and SiC nanoparticles on the microstructure and properties of A12O3 ceramic hybrid nanocomposites. Curr Appl Phys 16(12):1649-1658

[57] Liu Y, Shi K, Zhitomirshy I (2014) New colloidal route for electrostatic assembly of oxide nanoparticle: carbon nanotube composites. Colloids Surf A 446:15-22

[58] Wang W, Yamamoto G, Shirasu K, Nazaka Y, Hashida T (2015) Effects of processing conditions on microstructure, electrical conductivity and mechanical properties of MWCNT/alumina composites prepared by flocculation. J Eur Ceram Soc 35(14):3903-3908

[59] Du H-B, Li Y-L, Zhou F-Q, Su D, Hou F (2010) One-step fabrication of ceramic and carbon nanotube (CNT) composites by in situ growth of CNTs. J Am Ceram Soc 93(5):1290-1296

[60] Chen M, Yin X, Li M, Chen L, Cheng L, Zhang L (2015) Electromagnetic interference shielding properties of silicon nitride ceramics reinforced by in situ grown carbon nanotubes. Ceram Int 41(2):2467-2475

[61] Sun K, Yu J, Zhang C, Zhou X (2012) In situ growth carbon nanotube reinforced $\mathrm{SiCf} / \mathrm{SiC}$ composite. Mater Lett 66(1):92-95

[62] Ding D, Wang J, Xiao G, Li Z, Bai B, Ren J, He G (2019) Enhanced electromagnetic wave absorbing properties of $\mathrm{Si}-\mathrm{O}-\mathrm{C}$ ceramics with in-situ formed 1D nanostructures. Int J Appl Ceram Technol 17(2):734-744

[63] Parham H, Bates S, Xia Y, Zhu Y (2013) A highly efficient and versatile carbon nanotube/ceramic composite filter. Carbon 54:215-223

[64] Wei H, Yin X, Li X, Li M, Dang X, Zhang L, Cheng L (2019) Controllable synthesis of defective carbon nanotubes/Sc2Si2O7 ceramic with adjustable dielectric properties for broadband high-performance microwave absorption. Carbon 147:276-283

[65] Tofighy M, Mohammadi T (2015) Synthesis and characterization of ceramic/carbon nanotubes composite adsorptive membrane for copper ion removal from water. Korean $\mathbf{J}$ Chem Eng 32:292-298

[66] Zhang SC, Fahrenholtz W, Hilmas G, Yadlowsky E (2010) Pressureless sintering of carbon nanotube-A12O3 composites. J Eur Ceram Soc 30(6):1373-1380

[67] Ahmad I, Islam M, Dar M, Xu F, Shah S, Zhu Y (2015) Magnesia tuned multi-walled carbon nanotubes-reinforced alumina nanocomposites. Mater Charact 99:210-219

[68] Bakhsh N, Khalid F, Hakeem A (2014) Effect of sintering temperature on densification and mechanical properties of pressureless sintered CNT-alumina nanocomposites. IOP Conf Ser Mater Sci Eng 60(1):012059. https://doi.org/10. 1088/1757-899X/60/1/012059

[69] Balazsi C, Konya Z, Weber F, Biro L, Arato P (2003) Preparation and characterization of carbon nanotube reinforced silicon nitride composites. Mater Sci Eng C 23(6-8):1133-1137

[70] Jayaseelan D, Wang Y, Hilmas G, Fahrenholtz W, Brown P, Lee W (2011) TEM investigation of hot pressed- 10\% SiCZrB2 composite. Adv Appl Ceram 110(1):1-7

[71] Wang J, Kou H, Liu X, Pan Y, Guo J (2007) Reinforcement of mullite matrix with multi-walled carbon nanotubes. Ceram Int 33(5):719-722

[72] Laurent C, Peigney A, Dumortier O, Rousset A (1998) Carbon nanotubes-Fe-Alumina nanocomposites. part II: microstructure and mechanical properties of the hot-pressed composites. J Eur Ceram Soc 18(14):2005-2013 
[73] Ye F, Liu L, Wang Y, Zhou Y, Peng B, Meng Q (2006) Preparation and mechanical properties of carbon nanotube reinforced barium aluminosilicate glass-ceramic composites. Scr Mater 55(10):911-914

[74] Peigney A, Rul S, Lefevre-Schlick F, Laurent C (2007) Densification during hot-pressing of carbon nanotubemetal-magnesium aluminate spinel nanocomposites. J Eur Cer Soc 27(5):2183-2193

[75] An J-W, You D-H, Lim D-S (2003) Tribological properties of hot-pressed alumina-CNT composites. Wear 255(1-6):677-681

[76] Bi S, Su X, Hou G, Liu C, Song W-L, Cao M-S (2013) Electrical conductivity and microwave absorption of shortened multi-walled carbon nanotube/alumina ceramic composites. Ceram Int 39(5):5979-5983

[77] Duszova A, Dusza J, Tomasek K, Blugan G, Kuebler J (2008) Microstructure and properties of carbon nanotube/ zirconia composite. J Eur Ceram Soc 28(5):1023-1027

[78] Ma RZ, Wu J, Wei BQ, Liang J, Wu DH (1998) Processing and properties of carbon nanotubes-nano-SiC ceramic. J Mater Sci 33:5243-5246. https://doi.org/10.1023/A: 1004492106337

[79] Boccaccini A, Thomas B, Brusatin G, Colombo P (2007) Mechanical and electrical properties of hot-pressed borosilicate glass matrix composites containing multi-wall carbon nanotubes. J Mater Sci 42:2030-2036. https://doi. org/10.1007/s10853-006-0540-7

[80] Popov O, Vleugels J, Huseynov A, Vishnyakov V (2019) Reactive sintering of TiB2-SiC-CNT ceramics. Ceram Int 45(14):22769-22774

[81] Egorov S, Eremeev A, Kholoptsev V, Plotnikov I, Rybakov K, Sorokin A, Balabanov S, Rostokina E, Bykov Y (2021) Rapid microwave sintering of alumina ceramics with an addition of carbon nanotubes. Ceram Int 47(4):4604-4610

[82] Ghobadi H, Ebadzabeh T, Sadeghian Z, Barzegar-Bafrooei $\mathrm{H}$, Nemati A (2017) Microwave-assisted sintering of Al2O3-MWCNT nanocomposites. Ceram Int 43(8):6105-6109

[83] McInroy A, Rowley A, Freer R (2010) Enhanced microwave-assisted sintering of X7R ceramic dielectrics for use in multilayer capacitors. Ceram Int 36(6):2007-2010

[84] Zhang Z-H, Liu Z-F, Lu J-F, Shen X-B, Wang F-C, Wang Y-D (2014) The sintering mechanism in spark plasma sintering: proof of the occurrence of spark discharge. Scr Mater 81:56-59

[85] Zhan G-D, Kuntz J, Wan J, Mukherjee A (2003) Singlewall carbon nanotubes as attractive toughening agents in alumina-based nanocomposites. Nat Mater 2:38-42
[86] Zhan G-D, Kuntz J, Garay J, Mukherjee A (2003) Electrical properties of nanoceramics reinforced with ropes of singlewalled carbon nanotubes. Appl Phys Lett 83(6):1228-1230

[87] Gallardo-López A, López-Pernía C, Muñoz-Ferreiro C, González-Orellana C, Morales-Rodríguez A, Poyato R (2018) Spark plasma sintered zirconia ceramic composites with graphene-based nanostructures. Ceramics 1(1):153-164

[88] Momohimoh I, Saheb N, Hussein M, Laoui T, Al-Aqeeli N (2020) Electrical conductivity of spark plasma sintered $\mathrm{Al} 2 \mathrm{O} 3-\mathrm{SiC}$ and A12O3-carbon nanotube nanocomposites. Ceram Int 46(10):16008-16019

[89] Manafi S, Ebrahimi M, Bidabadi F, Mobasherpour I (2019) Structural properties and mechanical behavior of SWCNTs and MWCNTs reinforced A12O3 fabricated by spark plasma sintering. Ceram Int 45(13):15928-15933

[90] Lee K, Mo C, Park S, Hong S (2011) Mechanical and electrical properties of multiwalled CNT-Alumina nanocomposites prepared by a sequential two-step processing of ultrasonic spray pyrolysis and spark plasma sintering. J Am Ceram Soc 94(11):3774-3779

[91] Hussein M, Shahzad H, Patel F, Atieh M, Aqeeli N, Baroud T, Laoui T (2020) Porous Al2O3-CNT nanocomposite membrane produced by spark plasma sintering with tailored microstructure and properties for water treatment. Nanomaterials 10(5):845

[92] Saheb N, Hayat U (2017) Electrical conductivity and thermal properties of spark plasma sintered A12O3-SiCCNT hybrid nanocomposites. Ceram Int 43(7):5715-5722

[93] Sarkar K, Sarkar S, Das PK (2016) Spark plasma sintered multiwalled carbon nanotube/silicon carbide composites: densification, microstructure, and tribo-mechanical characterization. J Mater Sci 51:6697-6710. https://doi.org/10.1 007/s10853-016-9956-X

[94] Lanfant B, Leconte Y, Debski N, Bonnefont G, Pinault M, Mayne-L'Hermite M, Habert A, Jorand Y, Garnier V, Fantozzi G, Gallet SL, Bernard F (2019) Mechanical, thermal and electrical properties of nanostructured CNTs/ SiC composites. Ceram Int 45(2):2566-2575

[95] Rajukumar J, Belmonte M, Silimak J, Elias A, Cruz-Silva E, Perea-López N, Morelos-Gómez A, Terrones H, Endo M, Miranzo P, Terronas M (2015) 3D nanocomposites of covalently interconnected multiwalled carbon nanotubes with $\mathrm{SiC}$ with enhanced thermal and electrical properties. Adv Funct Mater 25(31):4985-4993

[96] Taheri M, Mazaheri M, Fard FG, Rezaie H, Schaller R (2014) High/room temperature mechanical properties of 3 Y-TZP/CNTs composites. Ceram Int 40(2):3347-3352

[97] Karanam A, Bicher L, Fong R (2015) On the densification behavior of $(0.2,0.5$, and $1 \mathrm{Wt}$ Pct) CNT-YSZ ceramic 
composites processed via spark plasma sintering. Metall Mater Trans B 46:1666-1673

[98] Holmes M (2019) Additive manufacturing continues composites market growth. Reinf Plast 63(6):296-301

[99] Wang X, Jiang M, Zhou Z, Gou J, Hui D (2017) 3D printing of polymer matrix composites: a review and prospective. Compos B Eng 110:442-458

[100] Li N, Li Y, Liu S (2016) Rapid prototyping of continuous carbon fiber reinforced polylactic acid composites by 3D printing. J Mater Process Technol 238:218-225

[101] Yu W, Zhou H, Li B, Ding S (2017) 3D printing of carbon nanotubes-based microsupercapacitors. ACS Appl Mater Interfaces 9(5):4597-4604

[102] Ye W, Wu W, Hu X, Lin G, Guo J, Qu H, Zhao J (2019) 3D printing of carbon nanotubes reinforced thermoplastic polyimide composites with controllable mechanical and electrical performance. Compos Sci Technol 182:107671. h ttps://doi.org/10.1016/j.compscitech.2019.05.028

[103] Zhu W, Fu H, Xu Z, Liu R, Jiang P, Shao X, Shi Y, Yan C (2018) Fabrication and characterization of carbon fiber reinforced $\mathrm{SiC}$ ceramic matrix composites based on $3 \mathrm{D}$ printing technology. J Eur Ceram Soc 38(14):4604-4613

[104] Gupta M (2017) 3D printing of metals. Metals 7(10):403. h ttps://doi.org/10.3390/met7100403

[105] Chen Z, Li Z, Li J, Liu C, Lao C, Fu Y, Liu C, Li Y, Wang P, He Y (2019) 3D printing of ceramics: a review. J Eur Ceram Soc 39(4):661-687

[106] Tu T, Jiang G (2018) SiC reticulated porous ceramics by $3 \mathrm{D}$ printing, gelcasting and liquid drying. Ceram Int 44(3):3400-3405

[107] Allahverdi M, Danforth S, Jafari M, Safari A (2001) Processing of advanced electroceramic components by fused deposition technique. J Eur Ceram Soc 21(10-11):1485-1490

[108] Blazdell P, Evans J, Edirisinghe M, Shaw P, Binstead M (1995) The computer aided manufacture of ceramics using multilayer jet printing. J Mater Sci Lett 14(22):1562-1565

[109] Anzar N, Hasan R, Tyagi M, Yadav N, Narang J (2020) Carbon nanotube: a review on synthesis, properties and plethora of applications in the field of biomedical science. Sens Int 1:100003. https://doi.org/10.1016/j.sintl.2020. 100003

[110] Roth R, Clark J, Field FR (1994) The potential for CMCs to replace superalloys in engine exhaust ducts. JOM 46:32-35

[111] Kumari L, Zhang T, Du G, Li W, Wang Q, Datye A, Wu K (2008) Thermal properties of CNT-alumina nanocomposites. Compos Sci Technol 68(9):2178-2183

[112] Shah W, Yang Y (2021) Microstructure, mechanical, and thermal properties of graphene and carbon nanotube- reinforced $\mathrm{A} 12 \mathrm{O} 3$ nanocomposites. J Mater Sci: Mater Electron 32:13656-13672

[113] Guo X, Cheng S, Cai W, Zhang Y, Zhang X (2021) A review of carbon-based thermal interface materials: mechanism, thermal measurements and thermal properties. Mater Des 209:109936. https://doi.org/10.1016/j.matdes.2021. 109936

[114] Hanzel O, Lofaj F, Sedlacek J, Kabatova M, Tatarkova M, Sajgalik P (2017) Mechanical and tribological properties of alumina-MWCNTs composites sintered by rapid hotpressing. J Eur Ceram Soc 37(15):4821-4831

[115] Momohjimoh I, Nouari S, Hussein M, Laoui T, Aqeeli N (2019) Thermal behavior of spark plasma sintered aluminabased nanocomposites. Arab J Sci Eng 44:6013-6028

[116] Zhan G-D, Mukherjee A (2005) Carbon nanotube reinforced alumina-based ceramics with novel mechanical, electrical, and thermal properties. Int J Appl Ceram Technol 1(2):161-171

[117] Jiang L, Gao L (2008) Densified multiwalled carbon nanotubes-titanium nitride composites with enhanced thermal properties. Ceram Int 34(1):231-235

[118] Sivakumar R, Guo S, Nishimura T, Kagawa Y (2007) Thermal conductivity in multi-wall carbon nanotube/silicabased nanocomposites. Scr Mater 56(4):265-268

[119] Pan Y, Wang J, Wang N, Liu Y, Wang C, He S, Cheng L (2019) Effects of aligned carbon nanotube microcolumns on mechanical and thermal properties of $\mathrm{C} / \mathrm{SiC}$ composites prepared by LA-CVI methods. J Eur Ceram Soc 39(16):5463-5467

[120] Nisar A, Ariharan S, Venkatesawaran T, Sreenivas N, Balani K (2017) Effect of carbon nanotube on processing, microstructural, mechanical and ablation behavior of $\mathrm{ZrB} 2$ 20SiC based ultra-high temperature ceramic composites. Carbon 111:269-282

[121] Ghobadi H, Nemati A, Ebadzadeh T, Sadeghian Z, Bafrooei H (2014) Improving CNT distribution and mechanical properties of MWCNT reinforced alumina matrix. Mater Sci Eng, A 617:110-114

[122] Djourlev N, Aman Y, Sillou D, Nédélec P (2012) Pore closure in spark plasma sintered alumina studied by variable energy positrons. Eur Phys J Appl Phys. https://doi. org/10.1051/epjap/2012110083ff.hal-00782523

[123] Yamamoto G, Omori M, Yokomizo J, Hashida T, Adachi K (2008) Structural characterization and frictional properties of carbon nanotube/alumina composites prepared by precursor method. Mater Sci Eng B 148(1-3):265-269

[124] Lee D, Yoon D (2014) Properties of alumina matrix composites reinforced with $\mathrm{SiC}$ whisker and carbon nanotubes. Ceram Int 40(9):14375-14383 
[125] Jiang D, Zhang J, Lv Z (2012) Multi-wall carbon nanotubes (MWCNTs)-SiC composites by laminated technology. J Eur Ceram Soc 32(7):1419-1525

[126] Lu Z, Jiang D, Zhang J, Lin Q (2009) Preparation and properties of multi-wall carbon nanotube/SiC composites by aqueous tape casting. Sci China Ser E Technol Sci 52:132-136

[127] Wang Y, Voronin G, Zerda T, Winiarski A (2005) SiC-CNT nanocomposites: high pressure reaction synthesis and characterization. J Phys Condens Matter 18(1):275-282

[128] Yazdani B, Xu F, Ahmad I, Hou X, Xia Y, Zhu Y (2015) Tribological performance of Graphene/Carbon nanotube hybrid reinforced A12O3 composites. Sci Rep 5:11579. h ttps://doi.org/10.1038/srep11579

[129] Chaudhary N, Dikshit M (2021) A state of art review on the graphene and carbon nanotube reinforced nanocomposites: a molecular dynamics approach. Mater Today Proc 47:3235-3241

[130] Arunkumar T, Pavanan V, Murugesan V, Mohanavel V, Ramachandran K (2021) Influence of nanoparticles reinforcements on aluminium 6061 alloys fabricated via novel ultrasonic aided rheo-squeeze casting method. Met Mater Int. 47:3235-3241. https://doi.org/10.1007/s12540-021-01 036-0

[131] Arunkumar T, Selvakumar T, Subbiah R, Ramachandran K, Manickam S (2021) Development of high-performance aluminium $6061 / \mathrm{SiC}$ nanocomposites by ultrasonic aided rheo-squeeze casting method. Ultrason Sonochem 76:105631. https://doi.org/10.1088/1757-899X/286/1/ 012034

[132] Szafran M, Bobzryk E, Kukla D, Olszyna A (2000) Si3N4A12O3-TiC-Y2O3 composites intended for the edges of cutting tools. Ceram Int 26(6):579-582

[133] Ariharan S, Nisar A, Balaji N, Aruna S, Balani K (2017) Carbon nanotubes stabilize high temperature phase and toughen A12O3-based thermal barrier coatings. Compos B Eng 124:76-87

[134] Nayim S, Hasan M, Seth P, Gupta P, Thakur S, Kumar D, Jamwal A (2020) Effect of CNT and TiC hybrid reinforcement on the micro-mechano-tribo behaviour of aluminium matrix composites. Mater Today Proc 21(3):1421-1424

[135] Leonov A, Khasanov A, Danchenko V, Khasanov O (2017) Spark plasma sintering of ceramic matrix composite based on alumina, reinforced by carbon nanotubes. IOP Conf Ser Mater Sci Eng 286:012034

[136] Chaudhury P, Samantaray S (2021) Modelling and optimization of machining of SiC-CNT conductive ceramic composite used for micro and nano sensor by electrical discharge machining. J Inst Eng India Ser D 102:437-452
[137] Samareh J, Siochi E (2017) Systems analysis of carbon nanotubes: opportunities and challenges for space applications. Nanotechnology 28(37):372001. https://doi.org/10.1 088/1361-6528/aa7c5a

[138] Thibeault S, Kang J, Sauti G, Park C, Fay C, King G (2015) Nanomaterials for radiation shielding. MRS Bull 40(10):836-841

[139] Li Z, Nambiar S, Zheng W, Yeow J (2013) PDMS/singlewalled carbon nanotube composite for proton radiation shielding in space applications. Mater Lett 108:79-83

[140] Al-Saleh M, Sundararaj U (2009) Electromagnetic interference shielding mechanisms of $\mathrm{CNT} /$ polymer composites. Carbon 47(7):1738-1746

[141] McClinton CR (2007) High speed/hypersonic aircraft propulsion technology development. Advances on propulsion technology for high-speed aircraft, NATO, USA

[142] Jin S, Son G, Kim Y, Kim C (2013) Enhanced durability of silanized multi-walled carbon nanotube/epoxy nanocomposites under simulated low earth orbit space environment. Compos Sci Technol 87:224-234

[143] Paul A, Jayaseelan D, Venugopal S, Solvas E, Binner J, Vaidhyanathan B, Heaton A, Brown P, Lee W (2012) UHTC composites for hypersonic applications. Am Ceram Soc Bull 91:22-29

[144] Gohardani O, Elola M, Elizetxea C (2014) Potential and prospective implementation of carbon nanotubes on next generation aircraft and space vehicles: a review of current and expected applications in aerospace sciences. Prog Aerosp Sci 70:42-68

[145] Spencer K (1947) Aircraft icing. J Glaciol 1(2):68-69

[146] Peak L, Ryerson C, Martel C (2002) Army aircraft icing, US

[147] Chu H, Zhang Z, Liu Y, Leng J (2014) Self-heating fiber reinforced polymer composite using meso/macropore carbon nanotube paper and its application in deicing. Carbon 66:154-163

[148] Yoon Y, Song J, Kim D, Kim J, Park J, Oh S, Han C (2007) Transparent film heater using single-walled carbon nanotubes. Adv Mater 19(23):4284-4287

[149] Yao X, Falzon B, Hawkins S, Tsantzalis S (2018) Aligned carbon nanotube webs embedded in a composite laminate: a route towards a highly tunable electro-thermal system. Carbon 129:486-494

[150] Larsson A, Delannoy A, Lalande P (2005) Voltage drop along a lightning channel during strikes to aircrafts. Atmos Res 76(1-4):377-385

[151] Gagne M, Therriault D (2014) Lightning strike protection of composites. Prog Aerosp Sci 64:1-16

[152] James A, Rajagopal S (2014) 1 - Gas turbines: operating conditions, components and material requirements. In: 
Structural alloys for power plants, Woodhead Publishing Series in Energy pp 3-21

[153] Yanar N, Kim G, Hamano S, Pettit F, Meier G (2003) Microstructural characterization of the failures of thermal barrier coatings on Ni-base superalloys. Mater High Temp 20(4):495-506

[154] Barnard P, Henderson M, Rodes N (2004) CMC integration and demonstration for gas turbine engines (CINDERS). Appl Therm Eng 24(11-12):1755-1764

[155] O’Donnell S, Sprong K, Haltli B (2004) Potential impact of carbon nanotube reinforced polymer composite on commercial aircraft performance and economics. In: AIAA 4th aviation technology, integration and operations (ATIO) Forum, Chicago

[156] Eakins E, Jayaseelan D, Lee W (2011) Toward oxidationresistant $\mathrm{ZrB} 2-\mathrm{SiC}$ ultra high temperature ceramics. Metall Mater Trans A 42:878-887

[157] Barraza O, Grasso S, Nasiri N, Jayaseelan D, Reece M, Lee W (2016) Sintering behaviour, solid solution formation and characterisation of TaC, HfC and TaC-HfC fabricated by spark plasma sintering. J Eur Ceram Soc 36(7):1539-1548

[158] Najpai S, Kundu R, Balani K (2020) Effect of B4C reinforcement on microstructure, residual stress, toughening and scratch resistance of (Hf, Zr)B2 ceramics. Mater Sci Eng A 796:140022. https://doi.org/10.1016/j.msea.2020. 140022

[159] Popov O, Vleugels J, Zeynalov E, Vishnyakov V (2020) Reactive hot pressing route for dense $\mathrm{ZrB} 2-\mathrm{SiC}$ and $\mathrm{ZrB} 2-$ SiC-CNT ultra-high temperature ceramics. J Eur Ceram Soc 40(15):5012-5019

[160] Upuda G, Rao S, Gangadharan K (2012) Future applications of carbon nanotube reinforced functionally graded composite materials. In: IEEE-international conference on advances in engineering, science and management (ICAESM -2012), pp 399-404

[161] Kim P, Lee D (2009) Composite sandwich constructions for absorbing the electromagnetic waves. Compos Struct 87(2):161-167

[162] Lu Z, Lu F, Cao J, Li D (2014) Manufacturing properties of turbine blades of carbon fiber-reinforced $\mathrm{SiC}$ composite based on stereolithography. Mater Manuf Process 29(2):201-209

[163] Nasiri N, Patra N, Jayaseelan D, Lee W (2016) Oxidation behaviour of $\mathrm{SiC} / \mathrm{SiC}$ ceramic matrix composites in air. J Eur Ceram Soc 36(14):3293-3302

[164] Stolzenburg F, Kenesei P, Almer J, Lee K, Johnson M, Faber F (2016) The influence of calcium-magnesium-aluminosilicate deposits on internal stresses in $\mathrm{Yb} 2 \mathrm{Si} 2 \mathrm{O} 7$ multilayer environmental barrier coatings. Acta Mater 105:189-198

[165] Goyal K, Singh H, Bhatia R (2020) Behaviour of carbon nanotubes-Cr2O3 thermal barrier coatings in actual boiler. Surf Eng 36(2):124-134

[166] Choudhary S, Islam A, Mukherjee B, Richter J, Arold T, Niendorf T, Keshri A (2021) Plasma sprayed Lanthanum zirconate coating over additively manufactured carbon nanotube reinforced Ni-based composite: unique performance of thermal barrier coating system without bondcoat. Appl Surf Sci 550:149397. https://doi.org/10.1016/j.apsusc. 2021.149397

Publisher's Note Springer Nature remains neutral with regard to jurisdictional claims in published maps and institutional affiliations. 